\title{
Measuring the Effects of Natural Gas Pipeline Constraints on Regional Pricing and Market Integration
}

\author{
Authors: Roger Avalos, Timothy Fitzgerald, and \\ Randal R. Rucker
}

NOTICE: this is the author's version of a work that was accepted for publication in Energy Economics. Changes resulting from the publishing process, such as peer review, editing, corrections, structural formatting, and other quality control mechanisms may not be reflected in this document. Changes may have been made to this work since it was submitted for publication. A definitive version was subsequently published in Energy Economics, [VOL\# 60, (November 2016)] DOI\# 10.1016/i.eneco.2016.09.017

Avalos, Roger, Timothy Fitzgerald, and Randal R Rucker. "Measuring the Effects of Natural Gas Pipeline Constraints on Regional Pricing and Market Integration." Energy Economics 60 (September 2016). DOI: 10.1016/j.eneco.2016.09.017. 


\title{
Measuring the Effects of Natural Gas Pipeline Constraints on Regional Pricing and Market Integration*
}

\author{
Roger Avalos ${ }^{\dagger}$ \\ Timothy Fitzgerald \\ Randal R. Rucker ${ }^{\S}$ \\ September 6, 2016
}

\begin{abstract}
Natural gas pipeline capacity sets physical limits on the quantity of gas that can be moved between regions, with attendant price effects. We find support for the hypothesis of integrated regional markets. Using data on daily pipeline flows and capacities in Florida and Southern California, we estimate reduced-form price effects of capacity constraints. We find that pipeline congestion increased realized citygate prices by at least 11 percent over the mean in Florida and by 6 percent over the mean in Southern California. We attribute the difference in price effects to more binding capacity constraints in the Florida pipeline network. Our estimates provide guidance for interstate pipeline investments.
\end{abstract}

Keywords: natural gas; pipelines; market integration; pipeline congestion

JEL Codes: Q40, L95

${ }^{*}$ The authors would like to thank seminar participants at the University of New Hampshire, the 31st USAEE/IAEE North American Conference, the Colorado School of Mines, and the WEAI 89th Annual Conference for constructive comments.

${ }^{\dagger}$ California ISO

¥Texas Tech University; Contact: timothy.fitzgerald@ttu.edu

$\S$ Montana State University, Department of Agricultural Economics and Economics 


\section{Introduction}

An extensive network of pipelines provides essential infrastructure for the operation of the natural gas market in the United States. Sweeping regulatory reforms in recent decades have restructured the market for the transportation services provided by these pipelines. These reforms notwithstanding, pipeline capacity sets physical limits on the quantity of gas that can be moved from production fields to end users. The potential impacts of pipeline capacity constraints on natural gas markets have long been recognized (Lyon and Hackett 1993; DeVany and Walls 1996; Marmer et al. 2007; Brown and Yücel 2008a). Market participants, industry analysts, and academic researchers have often asserted that breakdowns in market integration and periodically diverging prices result from binding pipeline capacity between particular hubs. In this paper, we use daily data on pipeline flows relative to capacity for markets in Florida and Southern California to obtain the first empirical estimates of the impacts of pipeline constraints on wholesale prices in regional markets.

The U.S. network of natural gas pipelines is extensive and constantly expanding. Increasing supply of natural gas due to technological advances and the concomitant increase in the quantity of natural gas demanded, combined with the regulatory lags associated with the expansion of pipeline capacity, make understanding the impact of pipeline capacity constraints a pressing issue. Important reserve additions from unconventional sources have changed the natural gas map and have provided the impetus for substantial investment in new pipeline capacity. Some capacity increases are the result of retrofitting existing pipelines to increase flow, while other expansions involve building new pipelines to link new producing regions with consumers. Focusing on new and expanded interstate pipelines entering service in 2007-2012, 121 Bcfd (billion cubic feet per day) of capacity was added along 13,163 miles, at a nominal cost of investment of $\$ 47.8$ 
billion. ${ }^{1}$ Those expansions increased the state-to-state capacity of natural gas pipelines by 15 percent and have accommodated consumption increases of 11 percent.

Not only do these investments costs billions of dollars, but they also entail substantial transaction costs. Makholm (2012) explains how obsolesence associated with asset specificity affects the incentives to invest in new pipelines. Klein et al. (1978) describe how the potential for opportunistic behavior arising from appropriable quasi-rents affects transaction costs and the resulting contractual arrangements. These factors, combined with the fact that - given current market institutions - quasi-rents created by scarce pipeline capacity largely do not accrue to pipeline owners and investors, may reduce the incentives to invest in additional capacity.

The flexibility and complexity of the natural gas pipeline network largely determine whether regional natural gas markets interact to form a single smoothly functioning national market. We conduct a series of cointegration tests and fail to reject the hypothesis that wholesale natural gas markets in the United States generally function as a single well-integrated national market. Our period of analysis covers a more recent period than previous studies, and some of our results are qualitatively similar (Doane and Spulber 1994; DeVany and Walls 1993 1996; Serletis and Rangel-Ruiz 2004; Cuddington and Wang 2006). Using daily prices from 14 regional markets over the period October 2006-August 2011, our results indicate that all market pairs are cointegrated, that the panel as a whole is cointegrated, and that possible regime shifts do not alter this result.

We then examine Florida and Southern California markets in more detail, using daily price and flow data to examine the price effects of limited capacity. Figures 1a and 1b display plots of regional wholesale market prices in Florida and Southern California, respectively, and the benchmark U.S. natural gas price at Henry Hub in Louisiana. From

\footnotetext{
${ }^{1}$ These estimates are derived from EIA natural gas pipeline projects available at http://www.eia.gov/ naturalgas/data.cfm.
} 
both of these plots, it is clear that the respective regional prices move together with the benchmark prices. It is also apparent - especially in Florida - that there are periods (typically brief) during which the regional price is substantially greater than the benchmark price.

In Florida, we find that the price is cointegrated with the Henry Hub price. We also estimate a reduced-form model of equilibrium Florida prices and find that, on average, pipeline congestion increased Florida wholesale prices by $\$ 0.79 / \mathrm{MMBtu}$ over the sample period, which represents an increase of 11 percent relative to the mean price. ${ }^{2}$

In Southern California, contrary to earlier studies, we find that prices are cointegrated with prices in other regional markets, suggesting that this region is currently integrated with the larger national market. Our estimate of the effect of binding pipeline constraints on Southern California prices is smaller than in Florida. At about $\$ 0.32 / \mathrm{MMBtu}$, the price increase is about 6 percent above the mean. The fact that there is only one day during the time span of our data, combined with other information presented below, suggests that capacity constraints in the Southern California market are less binding than those in Florida.

\section{Background}

Natural gas markets and pipelines in the United States have a long and important history, much of which is pertinent to understanding the current state of affairs. ${ }^{3}$ Briefly, prior to the 1980s, natural gas markets in the United States were regulated "from wellhead

\footnotetext{
${ }^{2} \mathrm{~A}$ price spike (or congestion rent) of $\$ 0.79$ is the most directly comparable estimate to our Southern California estimate. This estimate is also the most conservative estimate we obtain for Florida. Our other estimates of the magnitude of the congestion rents in Florida - obtained using more restrictive definitions of the threshold levels at which pipeline capacity becomes binding - are much larger, ranging as high as \$4.54/Mcf.

${ }^{3}$ McGrew (2009) provides a comprehensive review of the legal and regulatory environment in which natural gas pipelines have evolved. Makholm (2012) provides an institutional perspective on the history of pipelines. In appendix A, we describe the regulatory and contractual landscape pertinent to our study.
} 
to burnertip." Starting in the late 1970s and culminating in 1992 with FERC Order 636, natural gas markets underwent sweeping changes, most of which were focused on deregulating segments of the market. Today, wholesale natural gas markets are characterized by many producers and marketers competing to provide gas to a multitude of consumers. Spot and futures markets are available at dozens of locations and over a broad range of time horizons, providing price discovery and allowing for indexed contracts. Although interstate pipelines are still subject to regulation, ready access to transportation services and the ability of shippers to buy and sell their contracted primary transportation services on short notice in a secondary market allows the movement of gas between regions with substantial flexibility (Dahl and Matson 1998; Leitzinger and Collette 2002).

There are two strands of literature that are related to our empirical analysis. The first uses cointegration tests on prices to examine whether the reforms of natural gas markets that started in the 1970s have effectively resulted in the integration of regional markets into a single national market. Early studies in this area find that most markets became integrated fairly quickly during the post-deregulation periods they examined. Later studies by, for example, Marmer et al. (2007), Murry and Zhu (2008), and Brown and Yücel (2008a) find that the links between regional natural gas markets appear to have weakened over time. A common thread in these studies is that the markets that are not fully integrated are typically in California, the Rocky Mountains, and the Midwest. The explanation offered for this finding is typically that segmentation of natural gas markets is due to binding pipeline capacity constraints. One argument is that although there was ample excess interstate pipeline capacity in the early years after restructuring, over time as consumption grew, pipeline expansions did not keep pace. The resulting imbalance led to bottlenecks and pipeline congestion that reduced the ability to arbitrage between some regional markets. Our results suggest that these constraints have been relaxed, probably by the addition of additional miles of pipelines, to such an extent that the markets are again 
integrated.

The second strand of the literature directly examines the impacts of pipeline capacity on natural gas prices. Theoretical models designed to describe the workings of capacity-constrained pipeline systems are developed by Cremer and Laffont (2002) and Cremer et al. (2003). These studies focus on the analytics of price formation in relatively simple pipeline networks. A related study that estimates the price impacts of natural gas pipeline constraints is Oliver et al. (2014), which develops a structural model of pipeline constraints in a producing region. Whereas their model highlights the importance of transportation infrastructure investments, and the buffering effect that natural gas storage has on the market, our empirical analysis focuses on the effect of capacity constraints at the terminal end of the transport network, where consumers bear the brunt of price effects.

\section{Regional Market Model}

Regional markets for natural gas depend critically on the particular pipeline network serving the market. Weather-induced stochastic demand, especially for electricity generation and heating, drives the equilibrium outcomes we observe. The system engineering constraints involved in pipeline operation require a balance between the amount of gas injected and withdrawn. An important feature of these markets is that pipeline capacity constraints impose a limit on the quantity that can be delivered at any given time. Pipelines share attributes with other networks subject to congestion, such as electric grids and road networks (Joskow and Tirole 2000; Arnott et al. 1993). In the model developed below, we borrow from the framework for natural gas pipelines suggested by Cremer and Laffont (2002) and Cremer et al. (2003). We focus on the effects of capacity constraints in the short run and pricing considerations when multiple pipelines serve the same market.

Assume that deliveries to the regional natural gas market can be made from any of $i \in I$ 
serving pipelines. In a single time period, the total benefits of delivering the aggregate quantity $Q=\sum_{I} q_{i}$ is given by $B(Q)=\int_{0}^{Q} D(X) d X$, where $D(\cdot)$ is the regional demand for natural gas, and the marginal value of quantity $Q$ is $D(Q)$. Because aggregate benefits and marginal value depend on the aggregate quantity, deliveries of homogeneous gas from alternative suppliers are assumed to be perfect substitutes for one another in the product market. The costs of supplying gas are separable by the delivering pipeline, as characterized by $p_{i}^{S}=S_{i}\left(q_{i}\right)$. Because we focus on equilibrium price formation, the superscripts on price are superfluous. Each pipeline has a maximum capacity, given by $q_{i}^{c}$. In the short run, a regional market has an aggregate capacity constraint of $Q^{c}=\sum_{I} q_{i}^{c}$. Taking pipeline capacity as exogenous and ignoring the fixed costs of that capacity for now, the socially optimal equilibrium price will solve the constrained optimization problem:

$$
\max _{q_{i}} B(Q)-\int_{0}^{Q} \sum_{I} S_{i}\left(q_{i}\right) \quad \text { s.t. } q_{i} \leq q_{i}^{c} \forall i
$$

The Kuhn-Tucker conditions for each pipeline take the form:

$$
D(Q)-S_{i}\left(q_{i}\right)-\lambda_{i} \leq 0 \quad \lambda_{i}\left(q_{i}^{c}-q_{i}\right)=0
$$

If the capacity constraint on pipeline $i$ does not bind, then $\lambda_{i}=0$, where $\lambda_{i}$ represents the shadow value of an additional unit of capacity in pipeline $i$. We are interested in three cases that can arise. ${ }^{4}$

Case A - System Capacity Flow. All pipelines serving the regional market have capacity flows, which implies that the market price exceeds the marginal cost of supply and also that $D\left(Q^{c}\right)=S_{i}\left(q_{i}^{c}\right)+\lambda_{i} \forall i \in I$. The values of the $\lambda_{i}$ depend on the degree to which realized demand at $Q^{c}$ exceeds the individual $S_{i}\left(q_{i}^{c}\right)$ values.

\footnotetext{
${ }^{4} \mathrm{~A}$ graphical representation of a simple two-pipeline model is presented in appendix B.
} 
Case B - Subsystem Capacity Flows. One or more, but not all, pipelines servicing the market experience flows at capacity. Without loss of generality, consider the case where only pipeline $j \in I$ binds. Here, at the market clearing price, $D(Q)=S_{j}\left(q_{j}^{c}\right)+\lambda_{j}$ and $S_{i}\left(q_{i}\right)=S_{j}\left(q_{j}^{c}\right)+\lambda_{j} \forall i \neq j$.

Case C - No Capacity Flows. None of the pipelines serving the market have flows at capacity, so $D(Q)=S_{i}\left(q_{i}\right)$ and $\lambda_{i}=0 \forall i$. Flows will adjust so that marginal costs across pipelines will be equal, both to each other and to the market clearing price.

This simple framework offers two important hypotheses about price formation.

Hypothesis 1. When flow is at system capacity (Case A), the resulting regional market price will exceed the marginal delivery cost, with the difference being a function of the magnitude of the demand shock relative to system capacity.

Hypothesis 2. When increases in system flows cause some (but not all) pipelines to have binding flows (Case B), the equilibrium market price will exceed the marginal cost of delivery by an amount that increases with the difference in marginal costs between pipelines.

Figure 2 provides a graphical interpretation of the effects of a capacity constraint in a gas-importing region. ${ }^{5}$ For clarity, focus on daily variation in weather as a demand shifter. In periods of seasonable weather, demand is represented by $D_{L}$, and the intersection of supply and demand determines quantity and price $-Q^{0}$ and $p^{0}$. In periods with extreme heat or cold, demand might increase to $D_{H}$, and if there were no pipeline capacity constraints, the equilibrium quantity and price would be $Q^{1}$ and $p^{1}$. Pipeline capacity is the maximum quantity of gas that can be supplied, so the supply curve becomes vertical at $Q^{c}$. At the margin, the wholesale price must rise to $p^{c}$ so that the quantity demanded also

\footnotetext{
${ }^{5}$ To avoid graphical congestion, figure 2 abstracts from the fact that the regional market depicted may be comprised of several separate pipelines.
} 
equals $Q^{c}{ }^{6}$

We turn now to a set of issues pertaining to the scale and scope of the pipeline network. These are long-term issues, but we find it useful to develop two additional hypotheses to make predictions about how the network evolves over time. In figure 2 , the shaded area $C$ represents the total gains (in a single period) to pipeline companies, shippers, and wholesale consumers from expanding pipeline capacity to an amount greater than or equal to $Q^{1}$. This does not suggest that optimal capacity is $Q^{1}{ }^{7}$ The impact on price of optimal network scale is a Ramsey price that amortizes fixed investments in capacity (Cremer et al. 2003). We are interested in the impact of changes in the scale and scope of the network.

Hypothesis 3. When increases in system flows cause all pipelines to have binding flows (Case A), an increase in the total installed capacity $\left(Q^{c}\right)$ of the network will cause the equilibrium price to fall, holding constant demand.

Hypothesis 4. Holding demand and system capacity constant, increasing the number of pipelines in the system (I) will not increase the equilibrium price if the increase keeps marginal supply costs constant.

Capacity expansion may come with higher costs, but is predicted to reduce prices. The differences in costs as capacity increases are therefore important to understanding the likely effect on prices - some expansions may be intensive, allowing more gas to flow through existing lines. Extensive changes such as new pipelines will also expand total system capacity, but may have different marginal costs (and different Ramsey prices

\footnotetext{
${ }^{6}$ Because the prices in many contracts for transportation services are negotiated in advance, purchasers of some inframarginal units will pay a lower price, perhaps $p^{0}$. Others might pay a higher price. Our focus here is on the price of the marginal quantity of gas, and in the empirical analysis we use the average price of gas.

${ }^{7}$ The frequency with which Case A obtains, and the extent to which demand exceeds capacity today and is expected to exceed capacity in the future, can be translated into an expected demand versus installed capacity. The current costs of expanding capacity must then be compared to the discounted value of the welfare gains as measured by present and future values of $C$, with the socially optimal capacity expansion being the one that maximizes the difference.
} 
accounting for infrastructure costs). However, increasing the number of pipelines per se will not increase prices.

In our model to this point, price spikes would not be observed until the demand curve in figure 2 intersects the kink in the supply curve (where the capacity factor-the ratio of daily flow to capacity - reaches 1.00). Other important realities suggest at least three reasons why a price path like $S^{g}$ in figure 2 might be observed as flow approaches capacity - that is, why prices might rise before capacity constraints bind.

First, as demand shifts to the right from $D_{L}$ in figure 2, there will be an increasing number of transactions in the secondary market as increasingly scarce (and valuable) capacity is shifted from relatively low value users to higher value users through secondary market exchanges. The transaction costs for these exchanges are higher than those in the primary capacity market because the secondary transactions involve price negotiation. These higher transaction costs would cause observed prices to rise above the supply curve $(S)$ in figure 2 along a price path like $S^{g}$. Second, and closely related, the sellers of secondary contracts provide additional services relative to the services provided in primary-market contracts (Reiter and Economides 1999). The associated higher costs will also cause prices to rise along $S^{g}$ in figure 2 .

Third, in certain cases, a limited number of sellers may be able to exercise market power in the secondary market. Imagine that for each pipeline, a total of $m$ shippers subscribe the primary capacity. As flow approaches the capacity of the line, some subset of these shippers $m-k$ are willing to sell capacity. In case where $m-k$ is small or even equal to one, the possibility of market power is very real.

Our simple model highlights the importance of both demand and supply factors in determining prices and the transacted quantities of natural gas. Below, we extend our regional market model to an empirical specification that explicitly incorporates those factors. 


\subsection{Supply Factors}

Many factors affect natural gas production, including levels of reserves, labor and capital costs, historic drilling activities and production decline curves, government policy, and stochastic factors such as major weather events. At any given point in time, a benchmark price, such as Henry Hub, incorporates all relevant information, as well as expectations about future natural gas demand and supply conditions. An increase in the price at Henry Hub, insofar as it corresponds to (or causes) increased prices in other regions, will induce an increase in the quantity of natural gas supplied to all regions. This observation underscores the importance of the cointegration tests we conduct below. Holding constant the price at Henry Hub, an increase in price at a particular region (that is, an increase in the price basis differential between Henry Hub and the region) will lead to increased shipments of gas to that region.

Regional supply at time t $\left(Q_{t}^{S}\right)$ will therefore be a function of the price at Henry Hub $\left(p_{t}^{H H}\right)$, the regional price $\left(p_{t}\right)$, and other factors that interrupt supply $\left(\mathbf{X}_{t}\right)$, up to the

quantity $Q^{c}$ in figure 2, where the capacity constraint becomes binding, as in equation (2).

$$
Q_{t}^{S}= \begin{cases}S\left(p_{t}, p_{t}^{H H}, \mathbf{X}_{t}\right) & \text { if } S\left(p_{t}, p_{t}^{H H}, \mathbf{X}_{t}\right)<Q^{c} \\ Q^{c} & \text { if } S\left(p_{t}, p_{t}^{H H}, \mathbf{X}_{t}\right) \geq Q^{c}\end{cases}
$$

where $S\left(p_{t}, p_{t}^{H H}, \mathbf{X}_{\mathbf{t}}\right)$ is the regional supply function representing the aggregation of $S_{i}\left(q_{i}\right)$ from the $I$ pipelines serving the market. ${ }^{8}$ The proxy for supply interruptions $\left(\mathbf{X}_{t}\right)$ we use in our empirical analysis is the level of shut-in production in the Gulf of Mexico due to hurricanes (Brown and Yücel 2008b).

\footnotetext{
${ }^{8}$ An alternative way to specify the problem is as a function of regional basis differentials, or $p_{t}-p_{t}^{H H}$. See Oliver et al. (2014).
} 


\subsection{Demand Factors}

A number of factors affect the demand for natural gas in both the short and long run, including economic activity and incomes, prices of energy substitutes, and weather variation that drives demand for heating and cooling. The wholesale demand for natural gas is represented in equation (3).

$$
Q_{t}^{D}=f\left(p_{t}, P_{t}^{\text {oil }}, P_{t}^{\text {coal }}, \text { Income }_{t}, P_{t}^{E}, P_{t}^{I}, \text { Weather }{ }_{t}\right)
$$

The prices of oil and coal, which are long-run substitutes for natural gas in these sectors, are denoted by $P_{t}^{\text {oil }}$ and $P_{t}^{\text {coal }}$. Total personal income $\left(\right.$ Income $\left._{t}\right)$ is included as a demand shifter. Output prices in the electric and industrial sectors are represented by $P_{t}^{E}$ and $P_{t}^{I}$. Residential, commercial, and electric power demand are affected by weather conditions because natural gas and electricity are used both for space heating and for cooling.

\section{Empirical Strategy}

Our empirical analysis has two parts: first, we test for integration of different regional markets; then, we conduct reduced-form analyses of two specific regional markets.

\subsection{Cointegration Tests}

Testing to determine whether price series from two spatially distinct markets are cointegrated is a widely-used approach for examining the extent to which the two markets are integrated. ${ }^{9}$ Two non-stationary price series, $P_{i t}$ and $P_{j t}$, integrated of order $i$ and $j$, respectively, are cointegrated if there exists a linear relationship between them, as in equation (4), and if the errors from the relationship are integrated of order $i-j$

\footnotetext{
${ }^{9}$ Pesaran (2015) comprehensively addresses cointegration issues and estimation methods.
} 
$(I(i-j))$ (Engle and Granger 1987).

$$
\varepsilon_{t}=P_{i t}-\beta_{0}-\beta_{1} P_{j t}
$$

If wholesale markets efficiently distribute natural gas across regions, the difference in equilibrium prices will correspond to transportation and transaction costs. If those costs are constant over time, the relationship between upstream and downstream prices will be stationary. We are interested in the order of integration of the residuals $(\varepsilon)$ from a regression of the price in market $i$ on the the price in market $j$. If estimation of (5) yields a coefficient on $\alpha_{1}$ that is significantly less than one, then the series are cointegrated.

$$
\Delta \varepsilon_{t}=\alpha_{0}+\alpha_{1} \varepsilon_{t-1}+\sum_{j} \Delta \varepsilon_{t-j}+u_{t}
$$

The Augmented Dickey-Fuller (ADF) test in (5) is widely-used, thanks to the availability of appropriate critical values for the test statistic (Elliott et al. 1996). In addition, we report results from other commonly used tests: in particular, the Phillips-Perron (PP) test and the Kwiatkowski-Phillips-Schmidt-Shin (KPSS) test (Kwiatkowski et al. 1992). To compare all regional prices, we test whether the whole panel of 14 market prices - rather than just pairs of prices - is integrated using the test suggested by Nyblom and Harvey (2000).

We also employ tests developed by Gregory and Hansen (1996) and Kejriwal et al. (2012) that test for cointegration while allowing for the possibility of regime shifts in the price formation process. In our empirical application to capacity-constrained pipelines, it is possible that the data-generating processes for wholesale prices are not constant throughout the span of our data. Such regime shifts might occur, for example, due to changes in the demand regime depicted in figure 2. Regime shifts may also arise in response to changes in macroeconomic conditions or to structural changes in the natural gas market 
due, for example, to changes in the ability of buyers or sellers to exercise market power.

\subsection{Reduced-Form Model}

Regional price differences will be arbitraged away quickly if markets are competitive and integrated. Open access policies help ensure that pipeline access is competitive. ${ }^{10}$ With non-binding pipeline capacity constraints, the difference between prices in the upstream and downstream (with respect to pipeline flow) regions will be equal to the costs of transportation plus the transaction costs associated with arbitrage. When pipeline capacity is reached, the price difference is expected to become larger.

To identify the effects of capacity constraints, we estimate the reduced-form specification in equation (6) by OLS. The daily regional gas price is the dependent variable, and demand and supply factors (including one or more binary variables to indicate various levels of pipeline congestion) are explanatory variables. ${ }^{11}$

$$
\begin{aligned}
p_{i m t}= & \pi_{0}+\pi_{1} p_{t}^{H H}+\pi_{2} P_{t}^{\text {oil }}+\pi_{3} P_{i m}^{\text {coal }}+\pi_{4} \text { Income }_{i m}+\pi_{5} P_{i m}^{E}+\pi_{6} P_{i m}^{I}+\pi_{7} H D_{i m t} \\
& +\pi_{8} C D D_{i m t}++\pi_{9} \text { Hurricane Shutins } D_{t}+\pi_{10} \text { Binding Capacity } \text { Camt }_{i m}+\theta_{m}+\phi_{i m t},
\end{aligned}
$$

Here the $i$ subscript refers to the region (Florida or Southern California), $m$ refers to the month of the year, and $t$ refers to the day of the observation in our sample. To address

\footnotetext{
${ }^{10}$ As indicated in appendix A, "open access" refers to the requirement that pipeline companies offer their transportation service to all market participants. Due to the pro-rationing of oversubscribed capacity in open access pipelines, the assumption of competitiveness for pipelines that are likely to be at or near their full capacity generally seems warranted. We are assuming that there are always a sufficiently large number of shippers with subscribed capacity on the pipelines we study so that market power among primary capacity subscribers is not a concern. Incorporating market power would be a separate, interesting, and pertinent study.

${ }^{11}$ Our reduced form depends critically on the cointegration of the regional and benchmark prices. In the next section, we find robust support for the notion of cointegration under a number of alternative specifications. As a result, our regression results are consistent, and concerns associated with spurious regression are reduced (Greene and Zhang 2011).
} 
seasonality issues, we include month-of-year fixed effects represented by $\theta_{s}$. To account for changing macroeconomic conditions and trends, we include year fixed effects, $\phi_{y}$.

We define the pipeline capacity factor as the ratio of daily flow to daily stated capacity. We initially define Binding Capacity as a binary variable equal to one if the capacity factor is 0.95 or greater, and zero otherwise ${ }^{12}$ The estimated coefficient $\pi_{10}$ represents the average increase in prices on days when pipelines are congested and provides a direct estimate of the effect of such congestion on prices. In variants of equation (6), we examine the possibility that binding capacity constraints have different price impacts depending on the definition of the Binding Capacity variable. We also perform a number of robustness checks to investigate the possibility of nonlinear price reactions consistent with the "early" price increases depicted by the $S^{g}$ curve in figure 2 .

Identification in our model comes from two sources, each of which yields a testable prediction:

Prediction 1: Consider two days, both with identical values for all of the independent variables. Suppose that on the first day, demand in figure 2 is $D_{L}$. On the second day, a factor that affects demand, but is not included as an explanatory variable in equation (6), is different than on the first day. For example, suppose that the second day is a day in mid-July with the same temperature as the first day, but humidity is higher. This will cause the demand curve to shift to the right. If the second-day demand curve intersects the vertical portion of the supply curve in figure 2, the price of natural gas will rise by more than it would (from the same demand shift) if the pipeline constraint did not become binding, and the estimated value of $\pi_{10}$ will be positive.

Prediction 2: Consider two days on which all the independent variables are identical except that on the first day the capacity factor is 1.00. On the second day, capacity has

\footnotetext{
${ }^{12}$ We define the Binding Capacity variable in our base model in this manner to more easily compare our results for Florida and Southern California. See section 6.2 below for discussion of this issue.
} 
been expanded so that the same flow does not fill the pipeline. The predicted effect of this expansion is to reduce the wholesale price of natural gas.

\section{Data}

The natural gas price data we use for our analysis of the integration of natural gas markets were obtained from Natural Gas Intelligence (NGI), which are published by NGI as the Gas Daily Price Index. ${ }^{13}$ These data comprise daily prices for 14 hubs and market points in the United States for the time period from October 1, 2006 to August 29, 2011. The daily spot price at Henry Hub is one of the series we obtained, as are prices for the regional wholesale markets in Florida and Southern California that we use in our reduced form analysis of the impacts of pipeline capacity constraints on prices.

The price of electricity is a variable in equation (3) for which data are available monthly, but not daily. Instead of using monthly electricity prices, we posit that daily variation in electricity prices is likely to be an important determinant of daily variation in wholesale gas demand because of its use in the production of electricity. Lacking daily electricity prices, we capture the impacts of such daily variation in electricity prices with two weather variables that represent important short-term demand shifters. ${ }^{14}$

As proxies for weather factors that affect the demand for natural gas, we use daily temperature data from the National Oceanic and Atmospheric Administration to calculate daily cooling and heating degree days. The value of the cooling degree day (CDD) variable

\footnotetext{
${ }^{13}$ See Natural Gas Intelligence at http://www.naturalgasintel.com. Table D.1 in appendix D provides provenances for all variables used in the empirical analysis.

${ }^{14}$ Because Florida electricity markets were not restructured during the time period we examine, there is no source of daily electricity prices for Florida as there is in California. To maintain symmetry in our analyses between Florida and Southern California, we use the weather variables (described below) for both markets. Our primary regression specifications are similar in spirit to those estimated by Brown and Yücel (2008b); Hartley et al. (2008); Villar and Joutz (2006); Sebastian and Thoenes (2014), all of whom use weather variables similar to ours. Note also that the weather variables we use may reflect changes in the demand for natural gas through residential, commercial, and power sector demand, and not just through their indirect impact on electricity prices.
} 
is obtained by subtracting 65 from the actual temperature, with a lower bound of zero. An increase in the value of the CDD variable corresponds to days with higher temperatures and increased demand for cooling services, which we expect to increase natural gas demand by increasing electricity demand. The value of the heating degree day (HDD) variable is obtained by subtracting the average temperature for each day from 65 , with a lower bound of zero. As temperature falls, the calculated value of the HDD variable rises. This induces an increase in the demand for heating services by consumers, which increases the derived demand for, and the price of, natural gas.

Our measures of HDD and CDD differ from the typical calculation. We obtain daily HDD and CDD values for each weather station in Florida and Southern California and then average these across all the relevant stations in those two regions to calculate the variable values we use in our empirical analysis. ${ }^{15}$ With this approach, we observe some days with positive values of both HDD and CDD because of the spatial average across the market area. This is a more accurate indicator of natural gas demand than a simple average of all temperatures across the entire market area. In a dramatic example, a day on which the average temperature is 65 at every weather station across the market area is not the same as a day on which half the market area has a temperature of 100 and the other half has a temperature of 30. In both cases the average temperature is 65 degrees. Our measure would record such a day as having both heating and cooling demands, not a day with HDD and CDD values of zero.

The data on daily pipeline capacities and flows we use in our empirical analysis are provided by Lippman Consulting Inc. (LCI), which was a major supplier of natural gas data to industry participants. LCI collects data at receipt and delivery points, as well as at various compressor stations, for most interstate pipelines in the United States and Canada.

\footnotetext{
${ }^{15}$ We thank Joe Atwood at Montana State University for providing these data. Most other series, such as the NOAA series (http://www.ncdc.noaa.gov), average the mean daily temperatures from all stations and calculate a single state-wide HDD or CDD value.
} 
We use the LCI data to create a daily capacity factor measure, calculated as the daily flow rate divided by the stated daily capacity of the pipeline.

Figure 3 shows pipeline maps for the regional pipeline systems in our empirical study. Two interstate pipelines transport natural gas into Florida: Florida Gas Transmission Company (FGT) and Gulfstream Natural Gas System (Gulfstream). There are no interstate pipelines used to export gas from Florida, and natural gas production in the state accounts for less than 1 percent of in-state consumption. Moreover, there are no major storage or liquefied natural gas import facilities in the state. Table 1 describes capacity characteristics of the Florida pipeline system - capacity usage in each pipeline is listed separately, as well as in the combined system. Each of the two pipelines was at capacity on about 30 out of 961 days in our sample, and the system was full on nine days. The system was at 95 percent or more of capacity on 144 days in our data, which represents 15 percent of the observations we use in our analysis. The lower panel of the table records the changes in stated pipeline capacity over time.

In contrast, Southern California is served by four major interstate pipeline systems; Kern River, Transwestern, and two branches of the El Paso network (hereafter El Paso North and El Paso South). ${ }^{16}$ In addition, Pacific Gas and Electric Company has an intrastate pipeline (not shown in figure 3) that ships gas from southern to northern California. Unlike Florida, California has several storage facilities and also has significant marketed natural gas production. This production accounted for 12.6 percent of in-state consumption in 2010 .

Table 2 lists the four pipelines for which we have daily flow and capacity data. While two of the pipelines (Kern River and El Paso North) were regularly at their capacity, a third pipeline (El Paso South) was full on only 15 of the days in our sample, and the fourth

\footnotetext{
${ }^{16}$ An additional pipeline, Questar Southern Trails, also serves this market. It was excluded in part because of its relatively small size (80 MMcfd).
} 
(Transwestern) did not flow at its full capacity during the period covered by our data (January 2007 - August 2011). ${ }^{17}$ Further, the Southern California system was only at full capacity for one out of the 1164 observations in our data, and flow was above 95 percent of capacity on 48 days (4.1 percent of our observations). These observations suggest that the pipeline system capacity constraints in Southern California were considerably less binding than in Florida during the period of our analysis. Additional details for both the Florida and California pipeline networks are included in appendix C.

Tables 3 and 4 show summary statistics for the Florida and Southern California data. Although we received the same time span of data for both markets, we have fewer observations for Florida because there is a gap in the pipeline flow data for Florida. We have a single daily price for the two-pipeline Florida system that is the focus of our reduced form analysis and also a single price for the four-pipeline California system that we analyze. One interesting observation is that although the Florida citygate prices are higher than the corresponding Henry Hub prices, the Southern California citygate prices are lower. The gas shipped to California does not come directly from Henry Hub, but from other hubs further west. The use of the Henry Hub price as a benchmark is appropriate, however, because Henry Hub is widely agreed to be a national price discovery point. Moreover, as can be seen in figure 1b, the prices move together and the focus of our analysis is not on identifying the magnitude of the effect of Henry Hub prices on California prices, but on obtaining direct estimates of the effects of binding pipeline capacity constraints on prices in the two markets in our data set.

Daily spot West Texas Intermediate (WTI) oil prices were downloaded from the EIA's website $^{18}$ and converted from dollars per barrel to dollars per MMBtu using the standard

\footnotetext{
${ }^{17}$ Transwestern serves four power plant facilities in Arizona located downstream from the West compressor station. Our flow data are from the Arizona-California state line, but capacity is at the West compressor station. Although West is the point at which capacity binds, some portion of total flow is delivered in Arizona and not Southern California. This contributes to the appearance of flows below the stated capacity.

${ }^{18}$ http://www.eia.gov/dnav/pet/pet_pri_spt_s1_d.htm
} 
conversion factor of 5.8 MMBtu per barrel. Coal prices were obtained from EIA Form 923 Schedule 2 data on utility and non-utility generator fuel purchases, and are reported in $\$ /$ MMBtu. ${ }^{19}$ Total personal income data for Florida and California were obtained from the Bureau of Economic Analysis. The index of industrial output prices we use is from the Bureau of Labor Statistics, as is the producer price index (excluding energy) that we use to convert all prices (and personal income) to 2011 dollars. Insofar as oil and coal are (long-run) substitutes for natural gas, an increase in their prices is predicted to lead to an increase in the price of natural gas. Increases in incomes or industrial prices are expected to lead to increases in the demand for natural gas and in its price. Data for coal prices, the industrial output price index, personal income, and the producer price index are only available at monthly intervals. Because of the inconsistency in frequencies between the daily natural gas prices and the variables available only on a monthly basis, our primary regression specifications do not include the monthly variables. When we do include these variables, we find that (for Florida in particular) their estimated coefficients are generally not statistically significant. More importantly, for both Florida and Southern California, their inclusion does not substantively affect the estimated impacts of binding capacity constraints on natural gas prices.

A potentially important exogenous factor that can affect the supply of natural gas is hurricanes, which are an annual threat to natural gas production in historically important producing regions such as the Gulf of Mexico and along the Gulf Coast. To account for these impacts, we use weekly data from the Bureau of Ocean Energy Management, Regulation and Enforcement on the level of production shut-ins (in MMcfd) due to hurricanes. We convert the numbers posted weekly to a daily frequency by linearly interpolating between reports during hurricane season. Outside of hurricane season (December 1 - May 30) we assign this variable a value of zero.

\footnotetext{
${ }^{19}$ www.eia.gov/electricity/data/eia923/index.html
} 


\section{Results}

\subsection{Cointegration Results}

We conduct a battery of cointegration tests on a sample of prices from 14 U.S. pricing points for the period from 2006 to 2010. Using ADF tests, we find that all market prices are $I(1)$ in levels and $I(0)$ in differences, and that all individual price pairs are cointegrated. We also use a Nyblom-Harvey test (Nyblom and Harvey 2000) of whether the panel of U.S. natural gas markets is integrated. To balance the panel for this test, we drop two price series with missing data (Kingsgate and FGT Citygate). The test on the remaining 12 series rejects the null of no common trends among the price series with a test statistic of 19.84 (the critical value for 10 series at the 0.01 level is 3.14 ). ${ }^{20}$ These results provide evidence that the restructured U.S. wholesale natural gas market is integrated and generally functions as one market over the time span of our data. It is worth noting that these results do not preclude the possibility that there are binding bottlenecks along the systems of pipelines connecting the markets in our data. Any such bottlenecks, however, are not sufficiently strong or persistent to cause the statistical tests to suggest that natural gas markets are not well integrated over the entire period.

As a precursor to our reduced-form model, we subject the Florida and Southern California markets to additional analysis and present the results in table 5. In the ADF and Phillips-Perron tests, the null hypothesis is that the series are not cointegrated, so our results (which reject the null) indicate that both the Florida (FGT Zone 3 Citygate) prices and the Southern California prices are cointegrated with the Henry Hub price. Note that the estimated coefficient on the Henry Hub Price is significantly less than 1.0 for the Southern California regression. Rather than flowing directly from Henry Hub, gas is imported into Southern California from the Rockies, western Texas, and the Southwest.

\footnotetext{
${ }^{20}$ See tables D.3 and D.4 in appendix D for additional detail on these tests.
} 
Substituting the price at the Opal Hub in Wyoming in place of Henry Hub prices yields identical inference regarding the cointegrating relationship for the California series. We also conduct a KPSS test, the null hypothesis of which is that the relationship is stationary, and fail to reject the null for both Florida and Southern California.

An additional consideration is the possibility that there are structural breaks in the pricing process that might alter our conclusion to this point that the Henry Hub price is cointegrated with Florida and Southern California prices. To address this possibility, we use a test developed by Gregory and Hansen (1996), who demonstrate that if the true model includes a structural break, then the application of their test increases the power of the ADF tests. The G-H test allows for a single break in the structure of the pricing process and identifies the observation in the data set that yields the highest probability of accepting the null hypothesis of no cointegration of the prices. We consider structural breaks that involve intercept-only changes as well as intercept-and-slope changes. The results of these G-H tests support our previous findings that Henry Hub prices are cointegrated with Florida and Southern California. One interesting result is that the test discloses the most likely date of a structural break; we note that dates in early- to mid-2008 are the most likely times for both markets (see the bottom entries in table 5). These dates are in the midst of the Great Recession, suggesting that the structural breaks identified may reflect the impacts of changing macroeconomic conditions on natural gas markets.

It is also possible that there are multiple structural breaks in the pricing process over the period of our sample as a result of changing macroeconomic conditions or the other factors mentioned above. Kejriwal et al. (2012) suggest a test for cointegration in the presence of multiple structural breaks and provide the appropriate critical values. Using the days identified by the various Gregory-Hansen tests we ran as dates where there may have been structural breaks, we fail to reject the null of an unchanging unit root process over the whole sample. The most conservative Florida test statistic we obtain is 0.11 , whereas the 
critical value at the 0.05 level is 7.91. The same test performed on the California series yields a (most conservative) test statistic of 0.99 with a 0.05 critical value of 10.62 .

Summarizing, the cointegration tests discussed above indicate that the regional and benchmark prices are cointegrated. We take this as evidence of integration between the Florida and Southern California regional markets and the national market. Based on these results, we turn to our direct investigation of the effects of capacity constraints on regional prices.

\subsection{Reduced Form Results}

We estimate several variants of the reduced-form specification in equation (6), first for Florida, and then for Southern California.

\subsubsection{Florida}

The results for Florida support the predictions of the model discussed above. ${ }^{21}$ Consider first the results in model 1 of table $6 .^{22}$ All specifications include month-of-year fixed effects to control for seasonality of natural gas demand and prices, as well as year fixed effects to control for changing macroeconomic conditions and trends. ${ }^{23}$ The estimated coefficient on the Henry Hub price is positive and significant, as we expected. The

\footnotetext{
${ }^{21}$ Most of our analysis below treats the two Florida pipelines as a system. We do this because (1) we have a single natural gas price for the two Florida pipelines and (2) our examination (described below) of price effects from a single pipeline reaching capacity suggest that the interactions between capacity conditions in the two-pipeline system are important. The same comments and findings apply to our analysis of the four-pipeline Southern California system.

${ }^{22}$ Durbin-Watson tests on exploratory specifications indicated the presence of autocorrelation of the residuals, and White tests indicated that heteroskedasticity is also present. Accordingly, we report OLS estimates and use the Newey-West correction of standard errors for heteroskedasticity and autocorrelation in the reduced form results discussed below. The number of lags in our model is six, which is informed by our cointegration results, as well as by the rule of thumb (first proposed by Davidson and MacKinnon (1993)) of selecting the number of lags as the smallest integer that is greater than or equal to $T^{0.25}$, where $\mathrm{T}$ is the number of observations.

${ }^{23}$ December is the omitted month and 2006 is the omitted year. The month-of-year fixed effects are jointly significant, as are the year fixed effects.
} 
WT I Price is also positive and significant, consistent with the notion of gross substitution between natural gas and oil. ${ }^{24}$

The estimated coefficients on both the $H D D$ and $C D D$ variables are positive and significant, with the point estimate of $H D D$ being significantly larger. The estimated coefficient on Hurricane Shutins, which measures the impact on price of a one unit (Bcfd) increase in the volume of natural gas production that was shut-in on a given day as a result of hurricanes, is positive and significant. Gustav and Ike were the largest hurricanes during the period of our data. At the peak of their impact on production in September of 2008, our results suggest that the reduced production associated with these hurricanes increased prices in Florida by about $\$ 1.77(=0.25 \times 7.062)$.

The variable of primary interest in each of our regressions is the Binding Capacity variable, which is a binary variable that we assign a value of one when capacity is binding and a value of zero otherwise. In the first two models in table 6 we define binding capacity to correspond to capacity factors of 95 percent or greater (this definition allows us to directly compare our Florida results to the California results discussed below). In models 3 and 4, capacity is defined to be binding for capacity factors of 99 percent or greater, and in model 5 binding capacity corresponds to capacity factors of 100 percent or more. The estimated coefficients on the Binding Capacity variables in models 1, 3, and 5 support our prediction that pipeline constraints increase wholesale regional prices and indicate that binding capacity constraints have a large and statistically significant effect on FGT Zone 3 Citygate Prices. The average impact in model 1 , for example, is an increase of $\$ 0.79$, which is a nontrivial 11.3 percent of the average FGT price in our sample $(\$ 7.01)$. Comparing models 1, 3 and 5, one sees that as the capacity factor used to define the Binding Capacity

\footnotetext{
${ }^{24}$ The extent to which oil and natural gas are substitutes in the short run and long run is an issue that has received considerable attention from economists. See, for example Brown and Yucel (2008), Villar and Joutz (2006), Hartley et al. (2008), and Sebastian and Thoenes (2014). For our purposes, we note the sign and significance of the estimated coefficient on the WTI Price variable and focus our attention on the impacts of pipeline capacity constraints on natural gas prices.
} 
variable increases, so does the estimated impact of binding pipeline capacity on prices. ${ }^{25}$

In models 2 and 4 of table 6, we examine whether (as suggested by Prediction 1 from section 5.2 above) short-run demand shifters (specifically, $H D D$ and $C D D$ ) have greater impacts on prices on days when the Florida system is at or near capacity. In both models, the estimated coefficients on the multiplicative interaction terms between the Binding Capacity variable and the $H D D$ and $C D D$ variables are positive and statistically significant. ${ }^{26}$ This suggests - consistent with our prediction - that increases in HDD (indicating colder days) and in $C D D$ (indicating hotter days) have significantly greater impacts on prices when the pipelines are full or nearly so. We note that with the introduction of the multiplicative interaction terms, the estimated coefficients on the Binding Capacity variables in models 2 and 4 no longer represent the estimated price impacts of binding pipeline capacity. ${ }^{27}$

To further examine how capacity constraints affect prices, we estimate a series of regressions with flexible piecewise capacity factor variables and report the piecewise coefficient estimates from these regressions in table 7 (estimated coefficients on the other variables are not substantively affected and are not reported, but are available on request). In model 1 in table 7 , we include dummy variables for five bins of capacity between 75 and 100 percent in addition to the variable Total Capacity $100+\%$ discussed in table 6. Each coefficient measures the effect of flows at the indicated range of capacity on prices relative to prices when the daily capacity factor is less than 75 percent; for example, when the flow

\footnotetext{
${ }^{25}$ As a further test of our identification strategy, we estimate a specification like model 1, but without the three demand variables for which we have daily data (implying that a change in any demand variable that results in the capacity constraint being binding may be identifying the price effects of interest). The estimated coefficient on the capacity variable in this specification is somewhat larger, but is not statistically different than the estimates in table 6.

${ }^{26}$ We do not estimate these impacts for the model in which binding capacity corresponds to capacity factors of 100 percent or more because that would require estimating three coefficients with only eight observations.

${ }^{27}$ The implied estimates of the price impacts of capacity constraints from, for example, model 4 suggest that the impacts are significantly larger on very cold days than on very hot days. Moreover, a weighted average impact over all the days on which capacity was binding is very close to the corresponding estimate in model 3. Details on these calculations are provided in in the final subsection of appendix E.
} 
is between 85 and 90 percent of the stated pipeline capacity, prices are $\$ 0.40$ higher than when the flow is less than 75 percent of capacity. The estimated coefficients in model 1 reveal a monotonically increasing price function.

Note the very large jump in price $(\$ 5.32-\$ 0.98=\$ 4.34)$ when the flow increases from the $95-100 \%$ to the $100+\%$ capacity range. In models $2-4$ we include more narrowly defined bins in the highest near-capacity flow ranges to gain additional insights into the price increase as flow approaches capacity. The estimates in model 2 indicate that the price increase when flow is between 99 and 100 percent of capacity is almost twice as large as when flow is between 95 and 99 percent of capacity (\$1.66 vs. $\$ 0.85$ ).

There are nine observations in our sample with daily flow rates that are greater than or equal to the stated total capacity of the two Florida pipelines-observations for which our Total Capacity $100+\%$ variable takes a value of one. We also have 35 observations for which the flow is between 99 and 100 percent of capacity. In model 3 of table 7 , we split these 35 observations into two bins (the first with 17 observations, the second with 18). The estimated impact of increased flow on daily prices continues to increase monotonically in this model, and the jump in price when the pipeline network becomes completely full remains large $(\$ 5.47-\$ 1.86=\$ 3.61)$. In model 4 we create three bins with (approximately) equal numbers of observations. With this smaller number of observations in each bin, the monotonicity of the point estimates breaks down (though the point estimates are statistically non-decreasing), although the large increase in price as flows increase from near-capacity to full-capacity persists.

\subsubsection{Florida Capacity Expansion}

The next issue we investigate with the Florida data relates to our prediction that an increase in pipeline capacity will lead to a reduction in prices when capacity is binding. The bottom portion of table 1 shows that there is one instance during the time span of our 
data in which the increased capacity was large enough for us to estimate the impacts. This is the increase in capacity from 3,557 MMcfd to 4,280 MMcfd that took place early in April of 2011.

A straightforward approach to testing the prediction would be to estimate a regression that allowed the price effects of being at capacity to differ before and after the capacity increase in early April of 2011. This approach is precluded by the fact that there is only one observation for which flows were at 100 percent of the expanded capacity. ${ }^{28}$ Our data set includes 36 observations following the expansion in capacity early in April of 2011. For 12 of those observations, daily flows were less than the stated capacity before expansion. The average flow on these days was 3,355 MMcfd, which is 94.3 percent of the pre-expansion capacity and 78.4 percent of the increased capacity (see $Q_{2}$ in figure 4 ). Our earlier results (table 7) using capacity bins suggest that price effects increase as capacity factors increase. We predict that the post-expansion prices for these days will be lower than they would have been for the same flow levels prior to the expansion. Assuming the structure of the price effects as flows approach capacity did not change with the April 2011 expansion, we can actually predict the magnitude of the price reduction. ${ }^{29}$

Based on the regression estimates in model 1 of table 7 , prices on days when the average

\footnotetext{
${ }^{28}$ While we cannot conduct statistical tests with one observation, our prediction is supported in that the observed price after the expansion is less than the price on every one of the 31 days on which the capacity factor exceeded 99 percent in June-August of the preceding year.

${ }^{29}$ One reason for assuming that the structure of the price effects did not change is that the number of postexpansion observations in our data set (36) is too small to be able to reliably estimate five or more distinct post-expansion bin effects. The whole suite of cointegration tests presented in section 6.1 holds up around the capacity expansion with only one exception. That exception is the Gregory-Hansen test for a structural break in intercept-only after the expansion. All specifications of the test, both with and without additional independent variables in the cointegrating relationship, yielded the same result of no cointegration. This provides some evidence that the pipeline expansion itself may have changed the price generation process, but the power of this test is low with only 36 observations after the expansion. Gregory-Hansen tests allowing for either a regime break (intercept and slope), or a slope change alone, support the assumption that the pricing process did not change, suggesting that effects could be explained by a difference in slope, or in intercept and slope, if not by a change in intercept alone. This result suggests that our additional analysis is valid, because our models allow for regime shifts insofar as separate slope and intercept parameters are estimated below, and we find both are statistically significant.
} 
flow is between 90 and 95 percent of capacity are $\$ 0.55$ higher than when capacity is less than 75 percent. The point estimate of the difference between prices on days when flow is between 75 and 80 percent of capacity and days when flow is less than 75 percent of capacity is $\$ 0.04$. Thus, as illustrated in figure 4 , our prediction is that prices will be $\$ 0.51$ lower for this set of 12 post-expansion observations. ${ }^{30}$

The other 24 post-expansion observations all have daily flows greater than the pre-expansion capacity level, and all but one of those has a daily flow level less than the post-expansion capacity level. We omit from the ensuing analysis the one observation that had a flow level of 100 percent of the new capacity. The average flow rate of the other 23 observations is $3,780 \operatorname{MMcfd}\left(Q_{3}\right.$ in figure 4$)$ and the average of the capacity factor values for these days is 88.3 percent. The fact that the capacity factor for these 23 observations is lower after expansion than before (88.3 percent as compared to 100 percent or more) leads us to predict lower prices for these observations after the expansion in capacity. A more specific prediction can be obtained using the demand curve labeled $D_{3}$ in figure 4 . All 23 of the observations under consideration would have been at capacity prior to the expansion. Using the estimation results from model 1 in table 7 , the average price on days with flows at full capacity was $\$ 5.32$ higher than days with less than 75 percent capacity, while the price on days with flows between 85 and 90 percent of capacity was $\$ 0.40$ higher. Thus, we predict that prices for these observations will be lower than they would have been prior to the expansion by $\$ 4.92(=\$ 5.32-\$ 0.40) .{ }^{31}$

\footnotetext{
${ }^{30}$ Although the estimated price impact when flows are between 75 and 80 percent of capacity is not statistically different from zero, $\$ 0.04$ represents the best point estimate of the impact, so we use it for our calculations. Our conclusions are not altered if we assume this price impact is zero and then test whether the reduction in price after the expansion is equal to $\$ 0.55$.

${ }^{31}$ Note that points A and B represent two points on the same demand curve. The arc price elasticity of demand between these points is -0.12 , a value that is similar to estimates in the literature of the short-run demand for natural gas (Al-Sahlawi 1989).
} 
To test these two predictions, we estimate the following regression model

$$
\begin{aligned}
& p_{m t}=\mathbf{X}^{\prime} \pi+\pi_{10} \text { Flow }>\text { Old Capacity }_{m t}+\pi_{11} \text { Increased Capacity }_{m t} \\
& +\pi_{12}(\text { Flow }>\text { Old Capacity } \times \text { Increased Capacity })_{m t}+\theta_{m}+\phi_{y}+e_{m t}
\end{aligned}
$$

where $\mathbf{X}$ is the vector of covariates corresponding to $\pi_{0}$ to $\pi_{9}$ in equation (6).

Flow $>$ Old Capacity is a binary variable that we assign a value of one if the daily flow was at or above the pre-expansion binding capacity (for days both before and after capacity expanded). There are eight such days in our data prior to the April 2011 expansion and 24 such days after the expansion. Increased Capacity is a binary variable we assign a value of one for the 36 post-expansion observations in our sample. We also include a multiplicative interaction term.

We expect the Flow > Old Capacity coefficient to be positive and roughly equal to the estimated coefficients on the $100+\%$ Capacity variable in the regressions discussed above. The preceding discussion suggests the estimated coefficients $\pi_{11}$ and $\pi_{12}$ will be negative. Moreover, insofar as the structure of price effects does not change following the capacity expansion, we predict that (1) the Increased Capacity effect will be $-\$ 0.51$ and (2) the interaction term will be $-\$ 4.92$.

Because the estimated coefficients on other covariates are largely unchanged from previous specifications, table 8 presents the key coefficient estimates from a specification with the same covariates as in table 6 . All three of the estimated coefficients have the predicted signs. The estimated coefficient for the Flow > Old Capacity variable is $\$ 5.24$, which is statistically indistinguishable from the coefficients on the $100+\%$ Capacity variable in earlier specifications. The estimated coefficient on the Increased Capacity variable is $-\$ 0.51$, which is exactly equal to its predicted value. The estimated coefficient on the interactive term between these two variables is $-\$ 5.67$. Although this estimate is 
somewhat larger in absolute value than our predicted value of $-\$ 4.92$, the two values do not differ statistically. These results provide strong support for our predictions regarding the price impacts of increases in pipeline capacity.

Appendix E contains results from our analysis of two other issues related to our Florida data. First, is an examination of the impacts of including the "monthly" variables (coal price, income, and the industrial price index) in several of the specifications in table 6 . We find that the inclusion of these variables does not substantively affect our estimates of the price effects of pipeline capacity constraints. Second, is an investigation of the price effects of capacity constraints if one looks only at the individual pipelines, rather than at the system as a whole. We find that (1) the estimated price effects are substantially smaller if one focuses on capacity constraints in individual pipelines than if the focus is on the system's capacity constraints, and (2) there are substantial price effects due to interactions between flows in the two pipelines, but generally only when both pipelines are flowing at levels very close to capacity.

\subsubsection{California}

The specification we employ for California is very similar to the Florida specification - we use a binary indicator of days with average flow above 95 percent of stated capacity as a measure of pipeline congestion. As in the earlier Florida regressions, we include year and month-of-year fixed effects to control for trends and seasonality.

Starting with model 1 in table 9, the Henry Hub price is statistically significant, which is consistent with the results reported in table 5, and the discussion of those results applies here. The estimated coefficient on WTI Price is also positive and significant, as it was in Florida. The estimated coefficients on $H D D$ and $C D D$ are positive and statistically significant. Their estimated values - 0.028 and 0.041 - are considerably smaller than for Florida and are not significantly different from each other. 
The Southern California pipeline system for which we have data rarely reaches its stated capacity. From table 2, 48 of the 1164 days in the California sample have a capacity at or above 95 percent, so our coefficient estimates are averages over those days. The estimated value of the coefficient on the capacity variable indicates that prices are $\$ 0.32$ higher on days with flows that are more than 95 percent capacity than on days with lower flows. It is notable that the estimated coefficients on the capacity variable are virtually the same if the binary capacity variable is defined using 96 or 97 percent (results available on request from the authors). In table 6 we reported the estimated coefficient on the same capacity level in Florida capacity variable as $\$ 0.79$, which is 2.5 times larger than the coefficient for Southern California. This result supports hypothesis 1 in section 3. From tables 1 and 2, it can be inferred that pipeline capacity (or near capacity) constraints in the Florida system are more often binding than in the CA system. ${ }^{32}$ Under plausible assumptions, an implication of this is that in figure 2, on those days when the demand curve in California intersects the vertical portion of the supply curve, it is (on average) at a lower price than in the Florida system, which is consistent with our empirical results. ${ }^{33}$

In model 2 of table 9, we report the results from a regression with piecewise capacity factor variables designed to provide more information on how Southern California natural gas prices change as available capacity approaches zero. We include binary variables for three ranges (or bins) of capacity between 85 and 100 percent. The addition of two bins for capacity factor levels from 85 to 95 percent results in a statistically insignificant change in the value of the estimated coefficient on the $95+\%$ capacity variable. The estimated

\footnotetext{
${ }^{32}$ See, in particular, the top panels in tables 1 and 2 . There is only a single observation in our Southern California data where the system of pipelines is 100 percent full compared with nine if Florida. There are 44 observations in Florida where the system of pipelines has flows in excess of 99 percent of capacity, but only two in California. There are analogous differences between the two systems for other "near capacity" flow levels as far down as the "> $90 \%$ " rows in tables 1 and 2 .

${ }^{33}$ As with our Florida results, the addition of monthly variables to model 1 in table 2 does not substantively affect our estimate of the impact of binding capacity. In contrast to our Florida results, interactive terms between weather variables ( $H D D$ and $C D D$ ) and Binding Capacity $95+\%$ are not statistically significant. These results are available on request from the authors.
} 
coefficient on the 90 to 95 percent variable is $\$ 0.15$ and is statistically significant, while the coefficient on the 85 to 90 percent variable is not significant. So, while there is some evidence to support the presence of "early" price increases in Southern California, these only occur above 90 percent of the stated system capacity, and the magnitude of the increases are much smaller than for Florida. ${ }^{34}$ These results are consistent with capacity constraints being considerably less binding in Southern California than in Florida.

To this point in our analysis of California prices, we have investigated how prices change when the pipeline system as a whole approaches its capacity. In model 3, we examine whether prices are affected when the individual pipelines in the Southern California system have flows at or near their capacities. To do this, we construct the four 0-1 variables listed in table 9. We assign the variable Kern Capacity $100 \%$ a value of one when the capacity factor for Kern pipeline is 100 percent or greater and a value of zero otherwise. Similarly for the other three variables for the individual pipelines. We also include the variable Total Capacity $95+\%$ that was included in models 1 and 2. The estimated coefficients on the individual pipeline variables indicate that when any of the individual pipelines reach (or gets close to) their capacity, there is no significant effect on prices, but again, when the system as a whole gets close to its capacity, there is a significant increase (of $\$ 0.33$ ) in price.

In our analysis of Florida prices, we examined the impacts of an expansion in the capacity of the pipeline system in Florida. Table 2 indicates that there was an expansion in the capacity of the Kern River pipeline on April 9, 2010 from 2,042 to 2,917 MMcfd. Prior to that date, the Kern River pipeline was at capacity on 22 percent of the days in our sample. After that date, the pipeline was at capacity on only 5.3 percent of the days. Unfortunately, beyond this, we can say little about the impacts of the increase in capacity. As a result of declining production in the fields that provided gas for the El Paso North

\footnotetext{
${ }^{34} \mathrm{We}$ also estimate several specifications with further breakdowns of the 48 observations with capacity factors greater than 0.95 and (in contrast to Florida) find no indication of systematically increasing prices within this range.
} 
pipeline, flows were 22 percent lower in that pipeline after the Kern River pipeline was expanded (2,062 vs. 1,599 MMcfd). So, even though flows through Kern River increased after the expansion (from 1,998 to 2,084 MMcfd), total flow through the Southern California pipeline system decreased after the expansion. ${ }^{35}$ There were, in fact, no days after the Kern River expansion on which flows exceeded the initial capacity of the system (7,732 MMcfd). These circumstances preclude further analysis of the price impacts of the Kern River capacity expansion.

\section{Conclusion}

We find support for earlier research showing that restructuring in wholesale natural gas markets and open access pipelines have created arbitrage opportunities and integration between regional wholesale natural gas markets. Previous work identified regions where prices were not integrated with a national market, with several studies noting the balkanization of the Southern California market (DeVany and Walls 1996; Cuddington and Wang 2006; Marmer et al. 2007). In our analysis of a later time period, the Southern California market appears to be integrated into the larger national market, and gas flows into the region are rarely constrained by pipeline capacity. Our sample also indicates that prices at Kern River and Opal Hub in the Rockies are cointegrated with national prices, again in contrast to results from earlier periods. We find that regional markets in Florida and Southern California are integrated with a national market, even though substantial price increases occur in periods of high demand.

We conduct a reduced-form investigation of regional market pricing. In both Florida and Southern California, pipeline capacity constraints have immediate and significant absolute and relative price effects. We estimate effects in Florida of $\$ 0.79 / \mathrm{MMBtu}$ — which is about

\footnotetext{
${ }^{35}$ Average flows for the system before and after the Kern River expansion were 6,735 and 6,358 MMcfd.
} 
12 percent of the mean price - when flows exceed 95 percent of stated pipeline capacity. As we increase the threshold to 99 and then 100 percent of capacity, we estimate much larger price effects of $\$ 1.71$ and $\$ 4.54$, with the latter increase corresponding to 65 percent of the average observed price. In California the effects are more moderate, about $\$ 0.32 / \mathrm{MMBtu}$ - or 6 percent of the mean price-for 95 percent (or higher) capacity flow thresholds.

We are able to directly examine the short-run price effects of capacity expansions in Florida, and we find that following expansion the network reacted exactly as we would predict - days with binding capacity and price spikes became rare, and prices generally fell. However, in other markets (such as Boston) price spikes and congestion rents remain an important issue. ${ }^{36}$

If capacity expansions are effective in reducing the incidence of large price spikes, a natural question is why constraints persist. Our research on the particular market institutions, combined with our empirical analysis, lead us to three insights. First, the prices we observe are a mix of prices for primary capacity and prices in a secondary market. Gains from price increases in the secondary market due to constrained capacity do not accrue to the pipeline owners. Instead, the gains are captured by primary capacity owners (shippers), despite the intention of FERC Order 736.

Second, because many of the purchasers of wholesale gas are bound by guaranteed service contracts, their demand elasticity is small. However, these same purchasers are often protected by regulated rates that allow for averaging of acquisition costs. This mutes the signal to final consumers of gas, who might make different decisions if confronted with the full cost of consuming gas and scarce transportation capacity. Davis and Muehlegger (2010) have proposed an alternative pricing structure to address this second issue.

Third, despite substantial regulatory hurdles, over the time span of our data, we do observe non-trivial increases in pipeline capacity, especially in the Florida system we

\footnotetext{
${ }^{36}$ See, for example, Ailworth (2014); EIA (2013)
} 
examine. In the first three-and-a-half years of our Florida data, we observe one day on which the Florida system capacity factor was at 99 percent or more. Between June and October of 2010, we observe 34 days at this level of congestion, with the concomitant price increases that we estimate above. By early April of 2011, the capacity of the Florida system had been expanded by roughly 20 percent, after which there is only one day in our data on which the system reached its new capacity. Despite the particular institutions and the regulatory barriers in U.S. natural gas markets, there were sufficient incentives for pipeline owners in Florida to expand capacity when it became binding in 2010.

From our analysis, with the assistance of figures 2 and 4, we can provide insights into the magnitude of the costs and benefits from the 2011 capacity expansion in Florida. As discussed in section 6.2, our empirical estimates of the price effects of binding capacity are used to calibrate figure 4 . From this, we can estimate one component of the net social gains from capacity expansion - the portion of area $\mathrm{C}$ above $p^{1}$ in figure 2 (or triangle $\mathrm{ABC}$ in figure 4). Realizing that prices are measured in units of $\$ / \mathrm{Mcf}$, and quantities are in units of MMcf/day, this component of net social gains is $\$ 4.92 \times 1,000 \times(3,780-3,557) \times 0.5$ $=\$ 548,580$ per day. Our reduced form approach provides no information on the size of the portion of triangle $\mathrm{C}$ below $p^{1}$ in figure 2 - the other component of the net social gains from capacity expansion. Depending on the inelasticity of the short-run supply of natural gas relative to demand, this area may be larger or smaller than the upper portion of the triangle. Another critical component of a benefit-cost analysis is the cost of the 2011 FGT pipeline expansion, which was almost $\$ 2.5$ billion(EIA 20112015$).$

Distributional issues are also important and the rectangle to the left of $Q^{c}$ between $p^{1}$ and $p^{c}$, which represents a transfer from "producers" to consumers, is large $\$ 4.92 \times 1,000 \times(3,557)=\$ 17.5$ million per day - relative to the upper portion of triangle C. Our data provide no information on how that rectangle of congestion rents is divided between the pipeline owners and those shippers who were gaining from selling their 
capacity at high prices in the secondary market. That division, of course, has important implications for pipeline owners' incentives to invest in costly pipeline expansions.

With natural gas consumption expected to continue to increase in the future, decisions on whether or not to expand pipeline capacity will significantly affect regional market integration and pricing. Current transportation infrastructure was built to meet the requirements of past and current market conditions and policies. Increased production, especially from new regions, requires investment in additional pipeline capacity. Policy proposals that broadly affect natural gas markets, particularly those that lead to increased gas demand (e.g., stricter environmental standards that result in further displacement of coal-fired electric generation with natural gas), require an understanding of the impacts of pipeline constraints. Our analysis in this paper contributes to that understanding. More focused proposals might include changes to the regulatory structure of natural gas markets to improve transmission of price signals to firms making pipeline investment decisions. 


\section{References}

Ailworth, Erin, "Natural Gas Prices Spike," Boston Globe, January 10, 2014. Available at https://www.bostonglobe.com/business/2014/01/10/natural-gas-pricesspike/H8d7cjyAbnE8cnNliWzEHN/story.html.

Al-Sahlawi, Mohammed A., "The demand for natural gas: a survey of price and income elasticities," The Energy Journal, 1989, 10 (1), 77-90.

Arnott, Richard, Andre De Palma, and Robin Lindsey, "A structural model of peak-period congestion: A traffic bottleneck with elastic demand," The American Economic Review, 1993, 83 (1), 161-179.

Brown, Stephen P. A. and Mine K. Yücel, "Deliverability and Regional Pricing in US Natural Gas Markets," Energy Economics, 2008, 30 (5), 2441-2453.

_ and _, "What Drives Natural Gas Prices?," The Energy Journal, 2008, 29 (2), pp. 45-60.

Cremer, Helmuth and Jean-Jacques Laffont, "Competition in gas markets," European Economic Review, 2002, 46 (4), 928-935.

_ , Farid Gasmi, and Jean-Jacques Laffont, "Access to pipelines in competitive gas markets," Journal of Regulatory Economics, 2003, 24 (1), 5-33.

Cuddington, J.T. and Z. Wang, "Assessing the Degree of Spot Market Integration for US Natural Gas: Evidence from Daily Price Data," Journal of Regulatory Economics, 2006, 29 (2), 195-210.

Dahl, C.A. and T.K. Matson, "Evolution of the US Natural Gas Industry in Response to Changes in Transaction Costs," Land Economics, 1998, 74 (3), 390-408.

Davidson, Russell and James G MacKinnon, Estimation and Inference in Econometrics, New York, NY.: Oxford University Press, 1993.

Davis, L.W. and E. Muehlegger, "Do Americans Consume Too Little Natural Gas? An Empirical Test of Marginal Cost Pricing," The RAND Journal of Economics, 2010, $41(4), 791-810$.

DeVany, A. and W.D. Walls, "Pipeline Access and Market Integration in the Natural Gas Industry: Evidence from Cointegration Tests," Energy Journal, 1993, 14, 1-19.

_ and _ , "The Law of One Price in a Network: Arbitrage and Price Dynamics in Natural Gas City Gate Markets," Journal of Regional Science, 1996, 36 (4), 555-570.

Doane, Michael J. and Daniel F. Spulber, "Open Access and the Evolution of the U.S. Spot Market for Natural Gas," Journal of Law and Economics, October 1994, 37 (2), 477-517. 
Doane, M.J., R.P. McAfee, A. Nayyar, and M.A. Williams, "Interpreting Concentration Indices in the Secondary Market for Natural Gas Transportation: The Implication of Pipeline Residual Rights," Energy Economics, 2008, 30 (3), 807-817.

EIA, "New Natural Gas Pipeline Capacity Adds Service in Florida," Today in Energy, May 25, 2011. Available at http://www.eia.gov/todayinenergy/detail.cfm?id=1530.

_., "December Natural Gas Prices Spike in Boston," Today in Energy, December 6, 2013. Available at http://www.eia.gov/todayinenergy/detail.cfm?id=14071.

_, U.S. Natural Gas Pipeline Projects, Excel File Name:EIA-NaturalGasPipelineProjects.xls, U.S. Department of Energy, October 1, 2015. Available at http://www.eia.gov/naturalgas/data.cfm.

Elliott, Graham, Thomas J. Rothenberg, and James H. Stock, "Efficient Tests for an Autoregressive Unit Root," Econometrica, 1996, 64 (4), pp. 813-836.

Engle, R.F. and C.W.J. Granger, "Co-integration and Error Correction: Representation, Estimation, and Testing," Econometrica, 1987, pp. 251-276.

Greene, W.H. and C. Zhang, Econometric Analysis, Vol. 7, Upper Saddle River, NJ: Prentice Hall, 2011.

Gregory, Allan W. and Bruce E. Hansen, "Residual-based tests for cointegration in models with regime shifts," Journal of Econometrics, 1996, 70 (1), 99-126.

Hartley, Peter R, Kenneth B Medlock III, and Jennifer E Rosthal, "The relationship of natural gas to oil prices," The Energy Journal, 2008, pp. 47-65.

Joskow, Paul L. and Jean Tirole, "Transmission rights and market power on electric power networks," The Rand Journal of Economics, 2000, 31 (3), 450-487.

Kejriwal, M., P. Perron, and J. Zhou, "Wald tests for detecting multiple structural changes in persistence," Econometric Theory, 2012, 29 (1), 1-35.

Klein, Benjamin, Robert G. Crawford, and Armen A. Alchian, "Vertical Integration, Appropriable Rents, and the Competitive Contracting Process," Journal of Law and Economics, 1978, 21 (2), 297-326.

Kwiatkowski, Denis, Peter CB Phillips, Peter Schmidt, and Yongcheol Shin, "Testing the null hypothesis of stationarity against the alternative of a unit root: How sure are we that economic time series have a unit root?," Journal of Econometrics, 1992, 54 (1), 159-178.

Leitzinger, J. and M. Collette, "A Retrospective Look at Wholesale Gas: Industry Restructuring," Journal of Regulatory Economics, 2002, 21 (1), 79-101. 
Lyon, Thomas P. and Steven C. Hackett, "Bottlenecks and Governance Structures: Open Access and Long-Term Contracting in Natural Gas," Journal Law Economics ${ }_{6}$ Organization, 1993, 9 (2), 380-398.

Makholm, Jeff D., The Political Economy of Pipelines: A Century of Comparative Institutional Development, Chicago: University of Chicago Press, 2012.

Marmer, V., D. Shapiro, and P. MacAvoy, "Bottlenecks in Regional Markets for Natural Gas Transmission Services," Energy Economics, 2007, 29 (1), 37-45.

McGrew, J.H., FERC: Federal Energy Regulatory Commission, American Bar Association, 2009.

Murry, D. and Z. Zhu, "Asymmetric Price Responses, Market Integration and Market Power: A Study of the US Natural Gas Market," Energy Economics, 2008, 30 (3), $748-765$.

Nyblom, J. and A. Harvey, "Tests of common stochastic trends," Econometric Theory, 2000, 16 (2), 176-199.

Oliver, Matthew E, Charles F Mason, and David Finnoff, "Pipeline congestion and basis differentials," Journal of Regulatory Economics, 2014, 46 (3), 261-291.

Pesaran, M. Hashem, Time Series and Panel Data Econometrics, New York, NY: Oxford University Press, 2015.

Reiter, Doris F. and Michael J. Economides, "Structure and economics of the natural gas industry following deregulation," Advances in the Economics of Energy and Resources, 1999, 11, 161-186.

Sebastian, Nick and Stefan Thoenes, "What drives natural gas prices?A structural VAR approach," Energy Economics, 2014, 45, 517-527.

Serletis, A. and R. Rangel-Ruiz, "Testing for Common Features in North American Energy Markets," Energy Economics, 2004, 26 (3), 401-414.

Villar, Jose A and Frederick L Joutz, "The relationship between crude oil and natural gas prices," Energy Information Administration, Office of Oil and Gas, 2006, pp. 1-43. 


\section{Tables}

Table 1: Florida Pipeline Capacity Figures: Estimation Sample

\begin{tabular}{|c|c|c|c|}
\hline & FGT & Gulfstream & Total \\
\hline \multicolumn{4}{|c|}{ Days at Specified Capacity Factors } \\
\hline Capacity Factor & Days & Days & Days \\
\hline $100 \%$ & 29 & 31 & 9 \\
\hline$>99 \%$ & 43 & 116 & 44 \\
\hline$>98 \%$ & 56 & 147 & 59 \\
\hline$>97 \%$ & 66 & 176 & 78 \\
\hline$>96 \%$ & 78 & 203 & 116 \\
\hline$>95 \%$ & 105 & 227 & 144 \\
\hline$>90 \%$ & 228 & 357 & 246 \\
\hline
\end{tabular}

Pipeline Capacities

\begin{tabular}{lccc} 
As Of & MMcf/d & MMcf/d & MMcf/d \\
\hline $\mathbf{1 0 / 1 / 2 0 0 6}$ & 2,250 & 1,114 & 3,364 \\
$\mathbf{1 / 7 / 2 0 0 9}$ & 2,250 & 1,118 & 3,368 \\
$\mathbf{1 / 1 2 / 2 0 0 9}$ & 2,250 & 1,253 & 3,503 \\
$\mathbf{4 / 1 / 2 0 0 9}$ & 2,250 & 1,263 & 3,513 \\
$\mathbf{4 / 5 / 2 0 1 0}$ & 2,250 & 1,273 & 3,523 \\
$\mathbf{5 / 2 1 / 2 0 1 0}$ & 2,250 & 1,277 & 3,527 \\
$\mathbf{8 / 1 3 / 2 0 1 0}$ & 2,250 & 1,307 & 3,557 \\
$\mathbf{4 / 2 / 2 0 1 1}$ & 2,250 & 1,330 & 3,580 \\
$\mathbf{4 / 4 / 2 0 1 1}$ & 2,950 & 1,330 & 4,280 \\
$\mathbf{7 / 1 2 / 2 0 1 1}$ & 3,050 & 1,330 & 4,380 \\
\hline
\end{tabular}

Note: We calculate the daily capacity factor as the daily flow divided by the stated daily pipeline capacity, and then convert to percent. 
Table 2: Southern California Pipeline Capacity Figures: Estimation Sample

\begin{tabular}{|c|c|c|c|c|c|}
\hline & $\begin{array}{c}\text { Kern River } \\
\text { Veyo }\end{array}$ & $\begin{array}{l}\text { El Paso } \\
\text { North }\end{array}$ & $\begin{array}{l}\text { El Paso } \\
\text { South }\end{array}$ & $\begin{array}{c}\text { Transwestern } \\
\text { West }\end{array}$ & $\begin{array}{l}\text { Total } \\
\text { SoCal }\end{array}$ \\
\hline \multicolumn{6}{|c|}{ Days at Specified Capacity Factors } \\
\hline Cap. Factor & Days & Days & Days & Days & Days \\
\hline $100 \%$ & 197 & 298 & 15 & 0 & 1 \\
\hline$>99 \%$ & 575 & 375 & 21 & 0 & 2 \\
\hline$>98 \%$ & 714 & 418 & 27 & 0 & 8 \\
\hline$>97 \%$ & 818 & 454 & 32 & 0 & 16 \\
\hline$>96 \%$ & 889 & 487 & 41 & 3 & 30 \\
\hline$>95 \%$ & 949 & 524 & 48 & 25 & 48 \\
\hline$>90 \%$ & 1092 & 676 & 102 & 419 & 282 \\
\hline
\end{tabular}

\begin{tabular}{lccccc} 
& \multicolumn{5}{c}{ Pipeline Capacities } \\
As Of & MMcf/d & MMcf/d & MMcf/d & MMcf/d & MMcf/d \\
\hline $\mathbf{1 0 / 1 / 0 6}$ & 2,042 & 2,190 & 2,200 & 1300 & 7,732 \\
$\mathbf{4 / 9 / 1 0}$ & 2,197 & 2,190 & 2,200 & 1300 & 7,887 \\
\hline
\end{tabular}

Note: See notes from table 1.

Table 3: Florida Summary Statistics: Oct. 3, 2006 - Aug. 29, 2011

\begin{tabular}{lccccccc}
\hline \hline \multicolumn{1}{c}{ Variable } & Units & Source & Mean & Std. Dev. & Min. & Max. & N \\
\hline Florida Price & \$MMBtu & NGI & 7.011 & 2.861 & 2.333 & 18.081 & 961 \\
Henry Hub Price & \$MMBtu & NGI & 6.15 & 2.548 & 2.127 & 13.879 & 961 \\
WTI Price & \$MMBtu & EIA & 14.375 & 3.87 & 5.912 & 26.125 & 961 \\
Eastern Coal Price & \$MMBtu & EIA & 3.173 & 0.358 & 2.534 & 3.732 & 961 \\
FL Industrial Price & Index & BLS & 96.282 & 5.359 & 88.409 & 109.12 & 961 \\
FL Personal Income & Billion $\$$ & BEA & 0.755 & 0.031 & 0.713 & 0.802 & 961 \\
Heating Degree Days & HDD & NOAA & 2.522 & 4.825 & 0 & 27.57 & 961 \\
Cooling Degree Days & CDD & NOAA & 9.247 & 6.725 & 0 & 22.312 & 961 \\
Hurricane Shutins & Bcfd & BOEMRE & 0.214 & 0.884 & 0 & 7.062 & 961 \\
Total System Flow & MMcf/d & LCI & 2730.516 & 533.503 & 1563.141 & 4380.003 & 961 \\
Total System Capacity & MMcf/d & LCI & 3482.303 & 179.396 & 3364 & 4380 & 961 \\
Capacity Factor & Proportion & \multicolumn{7}{c}{0.782} & 0.136 & 0.465 & 1.073 & 961 \\
Binding Capacity 95+\% & Indicator & & $0.0 ? ?$ & $0.0 ? ?$ & 0 & 1 & 961 \\
Binding Capacity 99+\% & Indicator & \multicolumn{7}{c}{$0.0 ? ?$} & $0.0 ? ?$ & 0 & 1 & 961 \\
Total Capacity 100+\% & Indicator & 0.009 & 0.096 & 0 & 1 & 961 \\
\hline Notes: All prices in real 2011 dollars. The capacity factors and binary indicators for binding system capacity \\
are calculated from the LCI data. Binding Capacity $95+\%$ is a binary variable assigned a value of one if \\
daily flow is 95 percent or more of stated system capacity, and a value of zero otherwise. Binding Capacity \\
99+\% and 100+\% are defined similarly. The heating and cooling degree day measures are calculated from \\
NOAA weather station data- see discussion and illustrative example in the text.
\end{tabular}


Table 4: California Summary Statistics: Jan. 2, 2007 - Aug. 29, 2011

\begin{tabular}{lccccccc}
\hline \hline \multicolumn{1}{c}{ Variable } & Units & Source & Mean & Std. Dev. & Min. & Max. & N \\
\hline SoCal Price & \$MMBtu & NGI & 5.637 & 2.264 & 2.292 & 13.3 & 1164 \\
Henry Hub Price & \$MMBtu & NGI & 6.047 & 2.487 & 1.9 & 13.879 & 1164 \\
WTI Price & \$MMBtu & EIA & 14.445 & 3.826 & 5.397 & 26.125 & 1164 \\
Rockies Coal Price & \$MMBtu & EIA & 1.441 & 0.12 & 1.219 & 1.833 & 1164 \\
CA Industrial Price & Index & BLS & 96.803 & 8.132 & 82.337 & 115.657 & 1164 \\
CA Personal Income & Billion \$ & BEA & 1.643 & 0.05 & 1.571 & 1.72 & 1164 \\
Heating Degree Days & HDD & NOAA & 8.572 & 7.343 & 0.115 & 30.029 & 1164 \\
Cooling Degree Days & CDD & NOAA & 3.271 & 4.082 & 0 & 16.471 & 1164 \\
Total System Flow & MMcfd & LCI & 5836.85 & 845.864 & 3418.423 & 7087.747 & 1164 \\
Total System Capacity & MMcfd & LCI & 6409.547 & 898.024 & 4166.932 & 7341.928 & 1164 \\
Capacity Factor & Proportion & & 0.912 & 0.058 & 0.553 & 1.032 & 1164 \\
Binding Capacity 95+\% & Indicator & & 0.041 & 0.199 & 0 & 1 & 1164 \\
\hline
\end{tabular}

Notes: See notes to table 3. 
Table 5: Cointegration Tests for Florida and Southern California Prices with the Henry Hub Price

\begin{tabular}{|c|c|c|}
\hline Dependent Variable & Florida Price & SoCal Price \\
\hline Henry Hub Price & $\begin{array}{c}1.011^{* * *} \\
(0.016)\end{array}$ & $\begin{array}{c}0.885^{* * *} \\
(0.006)\end{array}$ \\
\hline Constant & $\begin{array}{c}0.785^{* * *} \\
(0.105)\end{array}$ & $\begin{array}{c}0.286^{* * *} \\
(0.041)\end{array}$ \\
\hline $\begin{array}{l}\text { Number of Observations } \\
\text { R-squared }\end{array}$ & $\begin{array}{c}960 \\
0.812\end{array}$ & $\begin{array}{l}1163 \\
0.945\end{array}$ \\
\hline $\begin{array}{l}\text { Test Statistics } \\
\text { ADF } \\
\text { Phillips-Perron }\end{array}$ & $\begin{array}{l}-11.211^{* * *} \\
-11.127^{* * *}\end{array}$ & $\begin{array}{l}-5.423^{* * *} \\
-4.211^{* * *}\end{array}$ \\
\hline $\begin{array}{l}\text { KPSS Test } \\
\text { Test Statistic } \\
\text { Lags }\end{array}$ & $\begin{array}{c}0.352 \\
18\end{array}$ & $\begin{array}{c}0.423 \\
21\end{array}$ \\
\hline $\begin{array}{l}\text { Gregory Hansen Test } \\
\text { Test Statistic } \\
\text { Break Date }\end{array}$ & $\begin{array}{c}-8.55^{* * *} \\
2 / 8 / 08\end{array}$ & $\begin{array}{l}-5.29^{* * *} \\
6 / 18 / 08\end{array}$ \\
\hline \multicolumn{3}{|c|}{$\begin{array}{l}\text { Notes: Both regional markets are tested for cointegration } \\
\text { with Henry Hub. California cointegration test results are } \\
\text { comparable when Opal prices is substituted for Henry Hub } \\
\text { prices. ADF and PP tests are performed on levels without } \\
\text { trend. } 1 \% \text { Critical Value: }-3.43 \text {. The KPSS test is conducted } \\
\text { on levels without trend. KPSS Critical Value: } 5 \%: 0.463 . \\
\text { Gregory-Hansen values and dates are reported including ca- } \\
\text { pacity factor and six fixed lags, determined using the ADF } \\
\text { test. *** p }<0.01\end{array}$} \\
\hline
\end{tabular}


Table 6: Florida: Determinants of Natural Gas Prices - All Pipelines

\begin{tabular}{|c|c|c|c|c|c|}
\hline & \multicolumn{2}{|c|}{ Binding Capacity $95+\%$} & \multicolumn{2}{|c|}{ Binding Capacity $99+\%$} & \multirow{2}{*}{$\frac{\text { Binding Capacity } 100+\%}{(5)}$} \\
\hline & (1) & $(2)$ & $(3)$ & (4) & \\
\hline Constant & $\begin{array}{c}-1.5399 * * * \\
(0.4380)\end{array}$ & $\begin{array}{c}-1.0758^{* * *} \\
(0.3868)\end{array}$ & $\begin{array}{c}-1.3189^{* * *} \\
(0.3520)\end{array}$ & $\begin{array}{c}-1.0375^{* * *} \\
(0.3213)\end{array}$ & $\begin{array}{c}-1.1360^{* * *} \\
(0.3093)\end{array}$ \\
\hline Real HH Price & $\begin{array}{c}1.0629^{* * *} \\
(0.0632)\end{array}$ & $\begin{array}{c}1.0696^{* * *} \\
(0.0562)\end{array}$ & $\begin{array}{c}1.0151^{* * *} \\
(0.0528)\end{array}$ & $\begin{array}{c}1.0117^{* * *} \\
(0.0497)\end{array}$ & $\begin{array}{c}1.0113^{* * *} \\
(0.0526)\end{array}$ \\
\hline Real WTI Price & $\begin{array}{c}0.0599^{* *} \\
(0.0242)\end{array}$ & $\begin{array}{c}0.0404^{* *} \\
(0.0200)\end{array}$ & $\begin{array}{c}0.0683^{* * *} \\
(0.0214)\end{array}$ & $\begin{array}{c}0.0582^{* * *} \\
(0.0202)\end{array}$ & $\begin{array}{c}0.0561^{* *} \\
(0.0226)\end{array}$ \\
\hline Heating Degree Days & $\begin{array}{c}0.1781^{* * *} \\
(0.0365)\end{array}$ & $\begin{array}{c}0.1043^{* * *} \\
(0.0211)\end{array}$ & $\begin{array}{c}0.1879 * * * \\
(0.0399)\end{array}$ & $\begin{array}{c}0.1618^{* * *} \\
(0.0426)\end{array}$ & $\begin{array}{c}0.1749^{* * *} \\
(0.0388)\end{array}$ \\
\hline Cooling Degree Days & $\begin{array}{c}0.1183^{* * *} \\
(0.0164)\end{array}$ & $\begin{array}{c}0.0962^{* * *} \\
(0.0153)\end{array}$ & $\begin{array}{c}0.1256^{* * *} \\
(0.0198)\end{array}$ & $\begin{array}{c}0.1212^{* * *} \\
(0.0204)\end{array}$ & $\begin{array}{c}0.1364^{* * *} \\
(0.0193)\end{array}$ \\
\hline Hurricane Shutins, Bcfd & $\begin{array}{c}0.3760^{* * *} \\
(0.0932)\end{array}$ & $\begin{array}{c}0.3287^{* * *} \\
(0.0984)\end{array}$ & $\begin{array}{c}0.3134^{* * *} \\
(0.0902)\end{array}$ & $\begin{array}{c}0.3018^{* * *} \\
(0.0933)\end{array}$ & $\begin{array}{c}0.3124^{* * *} \\
(0.0911)\end{array}$ \\
\hline Binding Capacity 95+\% & $\begin{array}{c}0.7853^{* * *} \\
(0.2257)\end{array}$ & $\begin{array}{c}-2.6523^{* *} \\
(1.1553)\end{array}$ & & & \\
\hline HDD $\times$ Binding Capacity $95+\%$ & & $\begin{array}{c}0.2870^{* * *} \\
(0.0851)\end{array}$ & & & \\
\hline CDD $\times$ Binding Capacity $95+\%$ & & $\begin{array}{c}0.1735^{* *} \\
(0.0695)\end{array}$ & & & \\
\hline Binding Capacity 99+\% & & & $\begin{array}{c}1.7130^{* * *} \\
(0.4807)\end{array}$ & $\begin{array}{l}-1.1257 \\
(2.1845)\end{array}$ & \\
\hline HDD $\times$ Binding Capacity $99+\%$ & & & & $\begin{array}{r}0.2563^{* *} \\
(0.1266)\end{array}$ & \\
\hline CDD $\times$ Binding Capacity $99+\%$ & & & & $\begin{array}{c}0.1203 \\
(0.1212)\end{array}$ & \\
\hline Binding Capacity 100+\% & & & & & $\begin{array}{c}4.5361^{* * *} \\
(1.0133)\end{array}$ \\
\hline $\mathrm{N}$ & 961 & 961 & 961 & 961 & 961 \\
\hline
\end{tabular}

Notes: The dependent variable in all regressions is the daily natural gas price for Florida for the period Oct. 6, 2006 - Aug. 29, 2011. Binding Capacity 95+\% is a binary variable assigned a value of one if daily flow is 95 percent or more of stated system capacity, and a value of zero otherwise. Binding Capacity $99+\%$ and $100+\%$ are defined similarly. Newey-West standard errors are in parentheses. All specifications include month-of-year fixed effects (with December as the excluded month), as well as year fixed effects (with 2006 as the excluded year). All prices are expressed in real 2011 dollars. ${ }^{* * *} \mathrm{p}<0.01$, ${ }^{* *} \mathrm{p}<0.05,{ }^{*} \mathrm{p}<0.1$. All $\mathrm{p}$-values are for two-tailed tests. 
Table 7: Determinants of Natural Gas Prices with Piecewise Capacity Measures: Florida - All Pipelines

\begin{tabular}{|c|c|c|c|c|}
\hline & $(1)$ & $(2)$ & $(3)$ & $(4)$ \\
\hline Binding Capacity 100+\% & $\begin{array}{c}5.3213^{* * *} \\
(1.0002)\end{array}$ & $\begin{array}{c}5.4498^{* * *} \\
(1.0207)\end{array}$ & $\begin{array}{c}5.4664^{* * *} \\
(1.0205)\end{array}$ & $\begin{array}{c}5.4593^{* * *} \\
(1.0224)\end{array}$ \\
\hline Capacity Factor $95-100 \%$ & $\begin{array}{c}0.9804^{* * *} \\
(0.2016)\end{array}$ & & & \\
\hline Capacity Factor $99-100 \%$ & & $\begin{array}{c}1.6584^{* * *} \\
(0.3101)\end{array}$ & & \\
\hline Capacity Factor $99.84-100 \%$ & & & $\begin{array}{c}1.8639^{* * *} * \\
(0.3611)\end{array}$ & \\
\hline Capacity Factor 99-99.84\% & & & $\begin{array}{c}1.4827^{* * *} \\
(0.3163)\end{array}$ & \\
\hline Capacity Factor $99.939-100 \%$ & & & & $\begin{array}{c}1.8243^{* * *} \\
(0.4520)\end{array}$ \\
\hline Capacity Factor 99.52-99.939\% & & & & $\begin{array}{c}2.1165^{* * *} \\
(0.3439)\end{array}$ \\
\hline Capacity Factor 99-99.52\% & & & & $\begin{array}{c}1.0354^{* * *} \\
(0.2892)\end{array}$ \\
\hline Capacity Factor 95-99\% & & $\begin{array}{c}0.8458^{* * *} \\
(0.2137)\end{array}$ & $\begin{array}{c}0.8529^{* * *} \\
(0.2135)\end{array}$ & $\begin{array}{c}0.8562^{* * *} \\
(0.2135)\end{array}$ \\
\hline Capacity Factor 90-95\% & $\begin{array}{c}0.5456^{* * *} \\
(0.1596)\end{array}$ & $\begin{array}{c}0.5929 * * * \\
(0.1551)\end{array}$ & $\begin{array}{c}0.5995^{* * *} \\
(0.1544)\end{array}$ & $\begin{array}{c}0.5994^{* * *} \\
(0.1547)\end{array}$ \\
\hline Capacity Factor $85-90 \%$ & $\begin{array}{c}0.3978 * * * \\
(0.1296)\end{array}$ & $\begin{array}{c}0.4472^{* * *} \\
(0.1232)\end{array}$ & $\begin{array}{c}0.4520^{* * *} \\
(0.1234)\end{array}$ & $\begin{array}{c}0.4498 * * * \\
(0.1231)\end{array}$ \\
\hline Capacity Factor $80-85 \%$ & $\begin{array}{c}0.2335^{* *} \\
(0.1065)\end{array}$ & $\begin{array}{c}0.2607^{* *} \\
(0.1058)\end{array}$ & $\begin{array}{c}0.2638^{* *} \\
(0.1059)\end{array}$ & $\begin{array}{c}0.2633^{* *} \\
(0.1060)\end{array}$ \\
\hline Capacity Factor $75-80 \%$ & $\begin{array}{c}0.0425 \\
(0.0775)\end{array}$ & $\begin{array}{c}0.0608 \\
(0.0756)\end{array}$ & $\begin{array}{c}0.0624 \\
(0.0756)\end{array}$ & $\begin{array}{c}0.0637 \\
(0.0756)\end{array}$ \\
\hline $\mathrm{N}$ & 961 & 961 & 961 & 961 \\
\hline
\end{tabular}

Notes: The dependent variable in all regressions is the daily natural gas price for Florida for the period Oct. 6, 2006 - Aug. 29, 2011. Binding Capacity 100+\% is a binary variable assigned a value of one if daily flow is 100 percent or more of stated system capacity, and a value of zero otherwise. Each Capacity Factor variable is a binary variable assigned a value of one if the flow level is in the indicated range and a value of zero otherwise. Newey-West standard errors are in parentheses. All specifications include month-of-year fixed effects (with December as the excluded month), as well as year fixed effects (with 2006 as the excluded year) and other covariates from table 6 . The piecewise capacity variables for capacity factors between 99 and 100 percent in models 3 and 4 are defined to have approximately the same number of observations in each binary bin. ${ }^{* * *} \mathrm{p}<0.01, * * \mathrm{p}<0.05$. All p-values are for two-tailed tests. 
Table 8: Florida Capacity Expansion Impacts

\begin{tabular}{|c|c|}
\hline & (1) \\
\hline Flow $>$ Old Capacity & $\begin{array}{c}5.2356^{* * * *} \\
(0.8807)\end{array}$ \\
\hline Increased Capacity & $\begin{array}{c}-0.5122^{* *} \\
(0.2005)\end{array}$ \\
\hline Flow $>$ Old Capacity $\times$ Increased Capacity & $\begin{array}{c}-5.6673^{* * *} \\
(0.8854)\end{array}$ \\
\hline $\mathrm{N}$ & 961 \\
\hline $\begin{array}{l}\text { Notes: The dependent variable is the daily } \mathrm{n} \\
\text { for the period Oct. } 6,2006 \text { - Aug. } 29,2011 \text {. } \\
\text { binary variable assigned a value of one if the } \\
\text { the pre-expansion capacity level and a value o } \\
\text { Capacity is a binary variable assigned a valu } \\
\text { capacity expansion and a value of zero otheru } \\
\text { errors are in parentheses. The regression spe } \\
\text { of-year fixed effects (with December as the e } \\
\text { year fixed effects (with } 2006 \text { as the exclude } \\
\text { from table } 6 \text { are also included and estimate } \\
\text { on request. } * * * \mathrm{p}<0.01, * * \mathrm{p}<0.05 \text { (two-tail }\end{array}$ & $\begin{array}{l}\text { Old Capacity is a } \\
\text { flow is greater than } \\
\text { therwise. Increased } \\
\text { e for days after the } \\
\text { wey-West standard } \\
\text { on includes month- } \\
\text { month), as well as } \\
\text { cients are available }\end{array}$ \\
\hline
\end{tabular}


Table 9: California: Determinants of Natural Gas Prices - All Pipelines

\begin{tabular}{lccc}
\hline \hline & $(1)$ & $(2)$ & $(3)$ \\
\hline Constant & $-0.6887^{* *}$ & $-0.7029^{* *}$ & $-0.6802^{* *}$ \\
& $(0.2989)$ & $(0.2960)$ & $(0.2969)$ \\
Real HH Price & $0.8613^{* * *}$ & $0.8657^{* * *}$ & $0.8639^{* * *}$ \\
& $(0.0326)$ & $(0.0334)$ & $(0.0334)$ \\
Real WTI Price & $0.0786^{* * *}$ & $0.0742^{* * *}$ & $0.0783^{* * *}$ \\
& $(0.0155)$ & $(0.0156)$ & $(0.0156)$ \\
Heating Degree Days & $0.0284^{* * *}$ & $0.0280^{* * *}$ & $0.0277^{* * *}$ \\
& $(0.0060)$ & $(0.0058)$ & $(0.0059)$ \\
Cooling Degree Days & $0.0412^{* * *}$ & $0.0372^{* * *}$ & $0.0406^{* * *}$ \\
& $(0.0094)$ & $(0.0096)$ & $(0.0094)$ \\
Binding Capacity 95+\% & $0.3201^{* * *}$ & $0.4060^{* * *}$ & $0.3258^{* * *}$ \\
& $(0.0943)$ & $(0.1107)$ & $(0.0878)$ \\
Capacity Factor 90-95\% & & $0.1477^{* *}$ & \\
Capacity Factor 85-90\% & & $(0.0732)$ & \\
& & 0.0232 & $(0.0510)$ \\
Kern at Capacity 100+\% & & & -0.0121 \\
& & & $-0.0419)$ \\
El Paso N at Capacity 100+\% & & & $(0.0648)$ \\
& & & 0.0371 \\
El Paso S at Capacity 100+\% & & $0.0747)$ \\
& & 0.0991 \\
Transwestern at Capacity $\geq 95 \%$ & & & $(0.0965)$ \\
& & & 1164 \\
\hline N & 1164 & 1164 & \\
\hline Notes: The dependent variable in all regressions is the daily natural
\end{tabular}
gas price for Southern California for the period Jan. 2, 2007 - Aug. 29, 2011. Binding Capacity $95+\%$ is a binary variable assigned a value of one if daily flow is 95 percent or more of stated system capacity, and a value of zero otherwise. Each Capacity Factor variable is a binary variable assigned a value of one if the flow level is in the indicated range and a value of zero otherwise. Each of the final four binary Capacity variables in the table is assigned a value of one when the respective individual pipeline is at the level indicated in the variable name. Newey-West standard errors are in parentheses. All specifications include monthof-year fixed effects (with December as the excluded month), as well as year fixed effects (with 2007 as the excluded year). All prices are expressed in real 2011 dollars. ${ }^{* * *} \mathrm{p}<0.01,{ }^{* *} \mathrm{p}<0.05,{ }^{*} \mathrm{p}<0.1$. All p-values are for two-tailed tests. 


\section{$9 \quad$ Figures}

Figure 1: Hub and Regional Market Prices

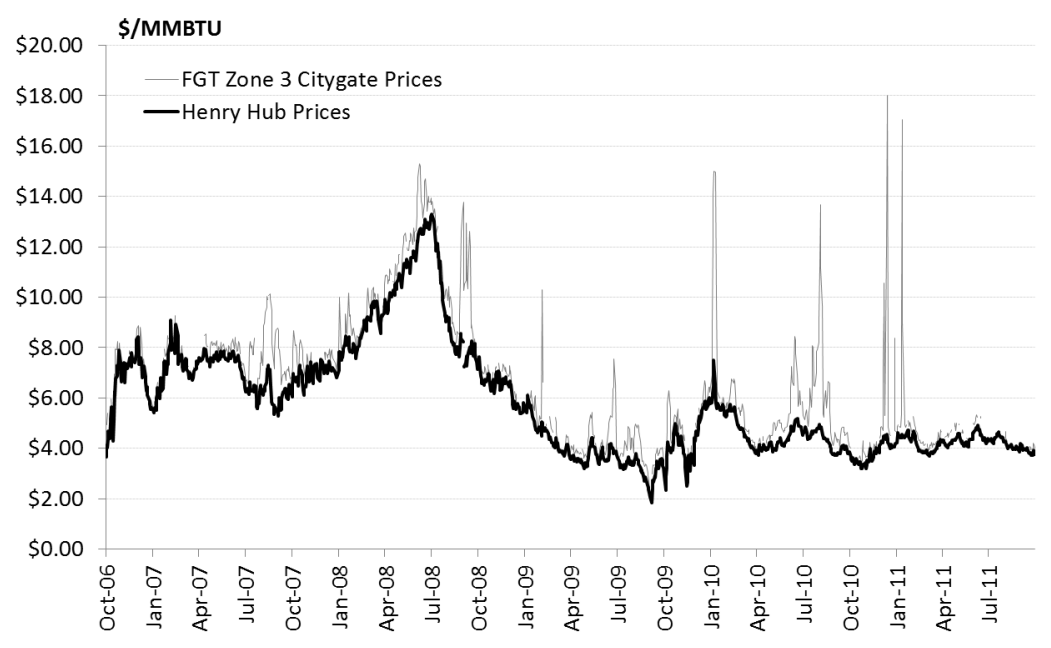

(a) Henry Hub and Florida Daily Gas Prices

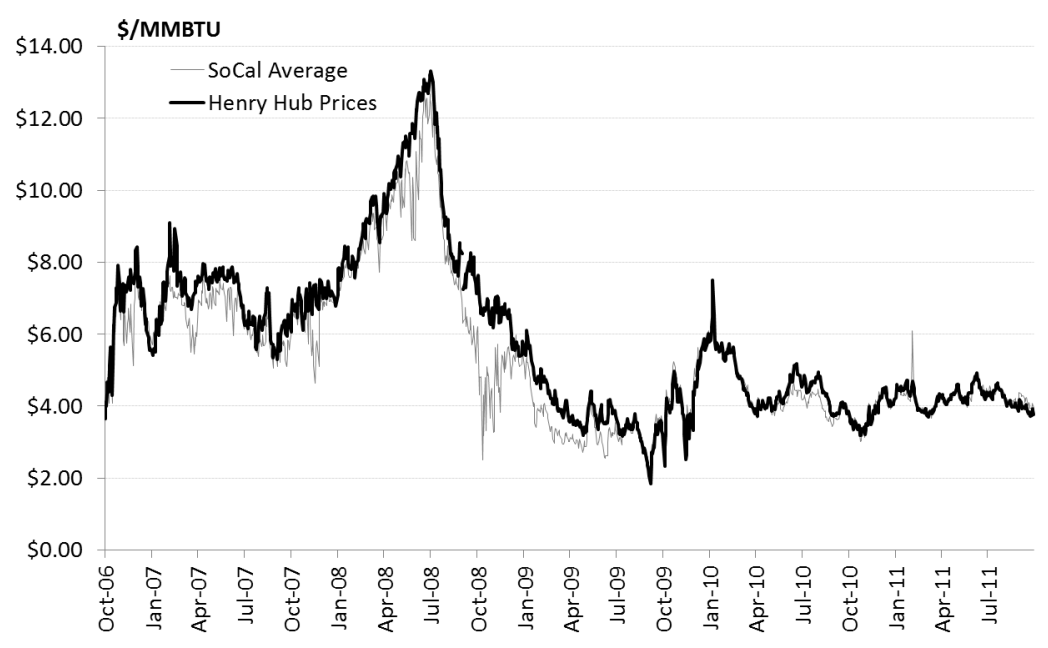

(b) Henry Hub and Southern California Daily Gas

Prices 
Figure 2: Representation of the Wholesale Natural Gas Market

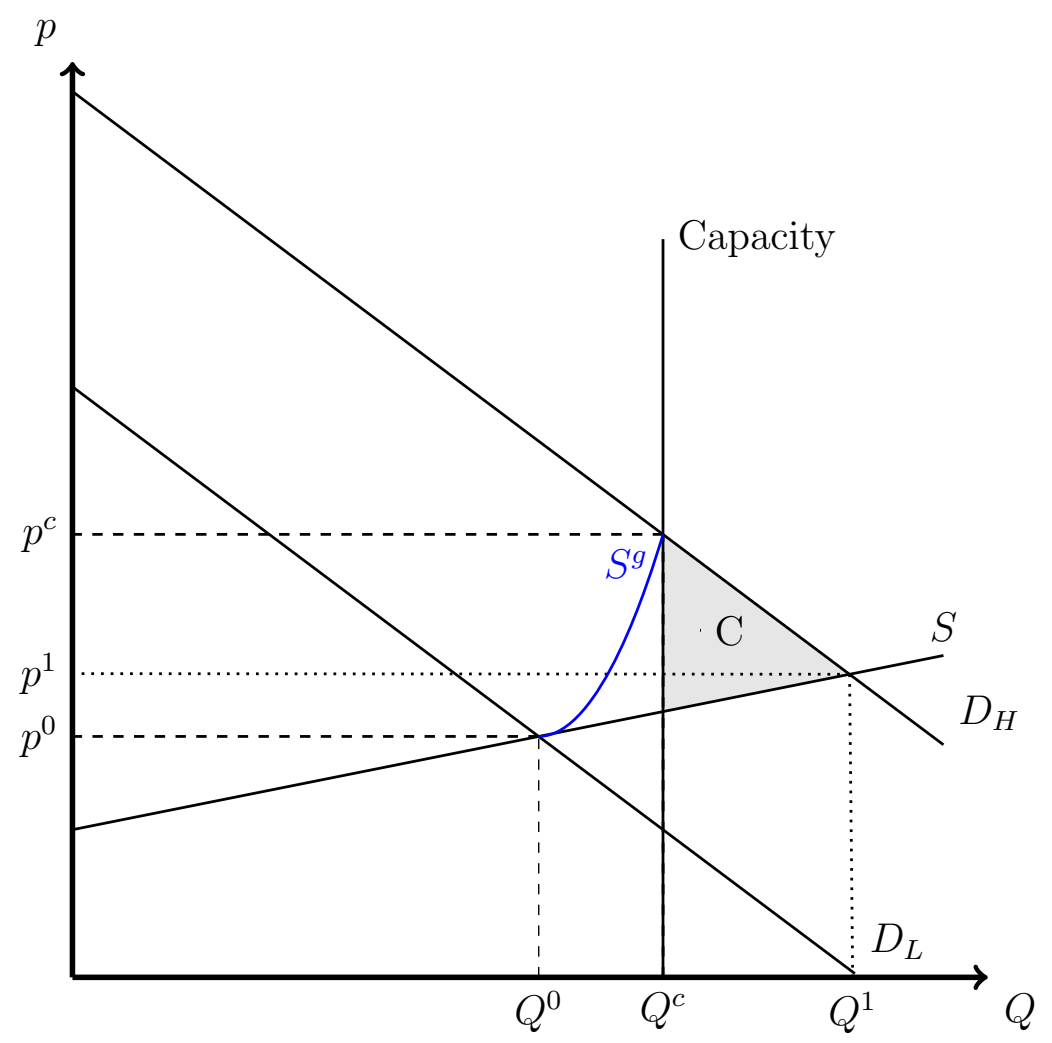


Figure 3: Stylized Map of Florida and Southern California Pipelines

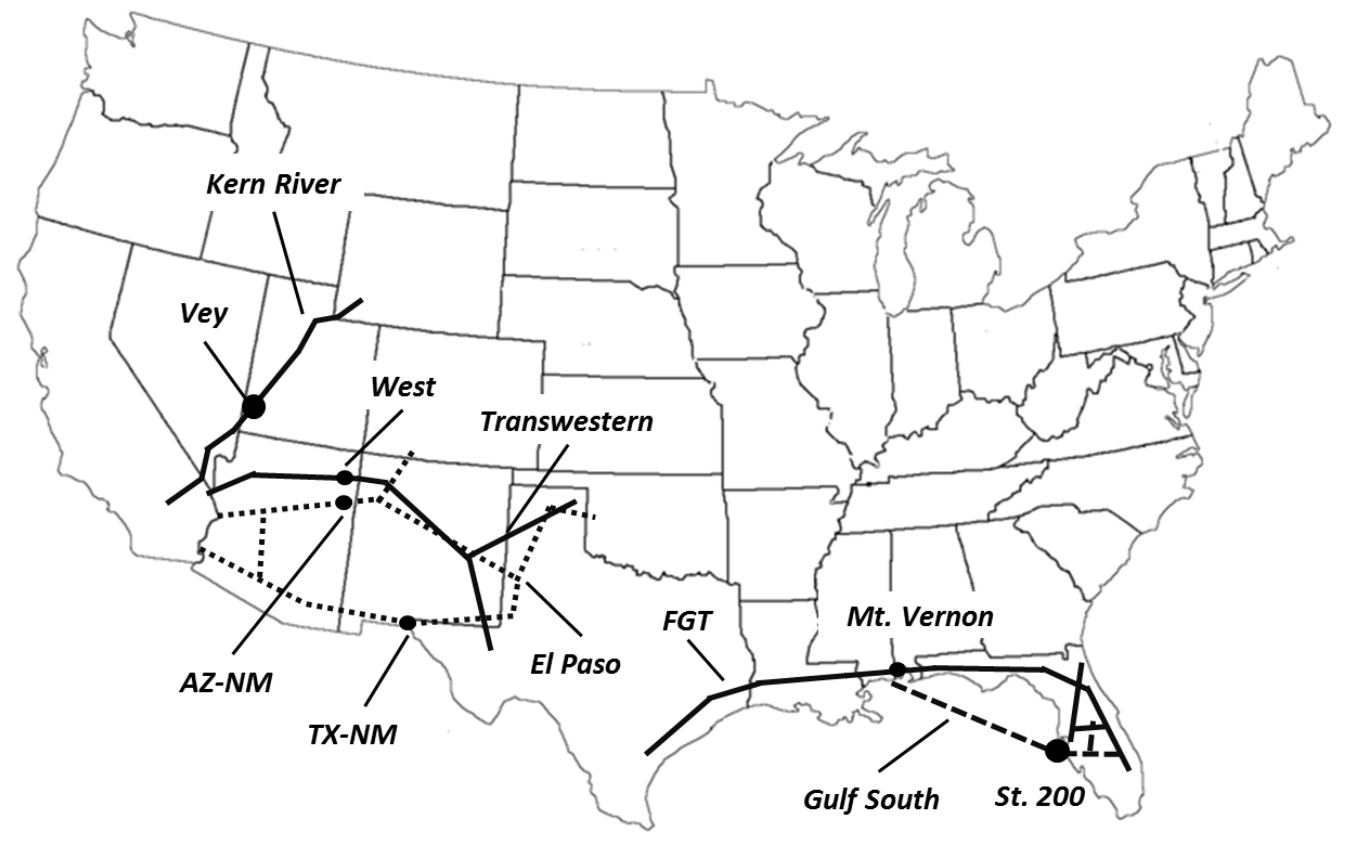


Figure 4: Florida Capacity Expansion Effects

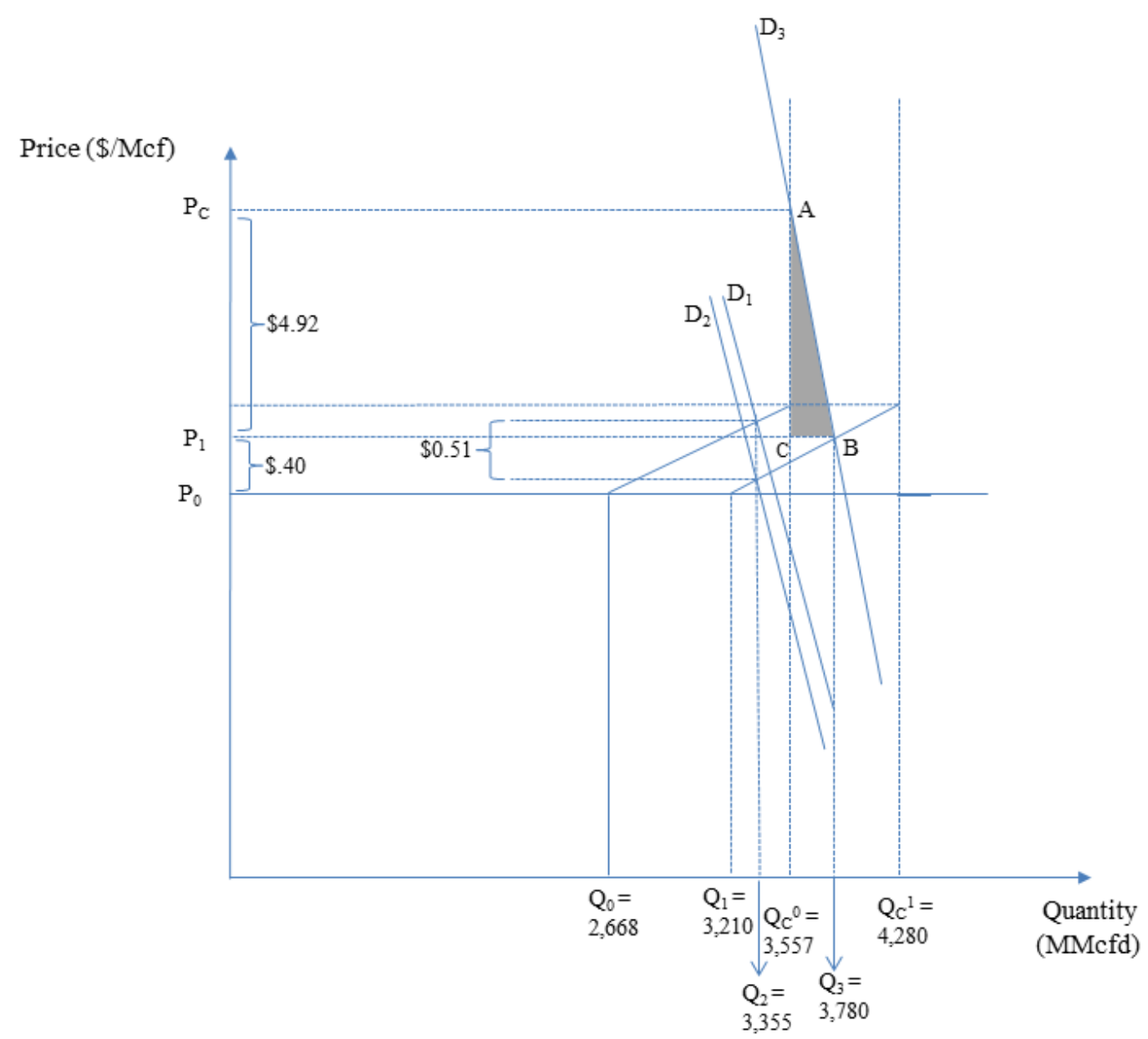




\section{Appendixes}

\section{A Regulatory Context}

Prior to the 1980s, producers did not sell their gas directly to gas consumers, or to local distribution companies (LDCs), who are important wholesale buyers. ${ }^{37}$ Instead, gas was initially sold to interstate pipeline companies at prices that, until 1989, were regulated by the Federal Energy Regulatory Commission (FERC). Pipeline companies then offered the entire range of merchant functions by providing the commodity, as well as transportation, storage, and portfolio management services to downstream gas buyers. Pipelines charged a single regulated rate for these bundled services, with their primary buyers being LDCs and industrial consumers. After buying gas from pipeline companies, LDCs sold gas to residential and commercial end-users at regulated rates.

Between 1978 and 1992, natural gas production and transportation markets were dramatically changed by a series of regulatory changes that allowed market forces greater sway. In the natural gas market, wellhead price controls were removed in 1984 by Order 436. In the market for gas transportation services, the owners of pipelines were required to decouple the transportation services they offered from commodity sales and other merchant functions. As a result, pipeline companies no longer take ownership of natural gas. They are now limited to providing transportation services for a (regulated) fee, and they are required to offer their transportation services to all market participants. This requirement of "open access" to transportation services has resulted in wholesale natural gas markets that, in the United States today, are characterized by many producers and marketers competing to provide gas to a multitude of customers through bilateral contracts covering a broad range of time horizons. In addition, spot and futures markets provide price discovery and allow for indexed contracts.

There are both primary and secondary markets for pipeline transportation services. As a rudimentary example of how these two markets function and relate to one another, suppose an LDC (the shipper in this scenario) purchases the primary right to ship a stated daily volume of natural gas from a producing region to the LDC's location during a specified time period, typically a month. This primary right can be firm or it can be interruptible. A shipper that purchases firm primary rights is guaranteed access to its

\footnotetext{
${ }^{37}$ McGrew (2009) and Makholm (2012) are good sources for additional details on the institutional information provided below.
} 
contracted daily transportation capacity for the duration of the contract. ${ }^{38}$ Interruptible service, on the other hand, allows the LDC to move a specified volume of gas within a specified time period, but the actual timing of the contracted gas transportation is at the discretion of the pipeline company.

A shipper may choose to purchase primary capacity, but due to fluctuating demand, there may be times when additional deliveries are less valuable than anticipated. In this case, two options are available to the shipper. First, the primary capacity can be released back to the pipeline company, which can then resell the capacity to another buyer. It is possible, though not guaranteed, that the original shipper could be reimbursed for up-front payments in this case. Alternatively, the LDC has the option of selling its primary contracted transportation services into a secondary market - an option it is most likely to choose to exercise during a period when there is a price spike (due, for example, to a binding pipeline capacity constraint). It is noteworthy that in this scenario, the party that gains from the price spike is the shipper, not the pipeline company. This feature of the secondary markets mutes a valuable signal for decisions regarding long-run pipeline investments. $^{39}$

The contract between the shipper and the transporter specifies a maximum daily quantity the shipper can transport. Pipeline transportation contracts typically consist of three parts. The first component - the reservation fee - is fixed with respect to both the quantity of gas actually shipped and the price of natural gas. The shipper is responsible for payment of the product of the reservation fee and the maximum daily quantity. The second component - the usage fee - varies with the quantity of natural gas actually shipped, but not with the price of natural gas. The shipper is also responsible for usage payments equal to the volume of natural gas actually shipped multiplied by the usage fee. The third component - the fuel reimbursement charge - varies with both the quantity of gas shipped and the price of natural gas. Because natural gas is used to operate the pipeline, the purpose of the variable charge is to compensate the pipeline for these costs. The buyer of the transportation service thus pays the fuel cost by providing this gas to the pipeline.

\footnotetext{
${ }^{38}$ As with many other types of contracts, force majuere is an exception. Further detail about the structure of transportation contracts is provided below.

${ }^{39}$ In 2010 FERC Order 736 was issued to allow pipeline companies to profit from released capacity, and thereby receive an important signal regarding investments in pipeline capacity expansions. Implementation as intended would have eliminated the secondary market and channeled all unused capacity back to the pipeline company for resale to other shippers. A substantial secondary market in capacity still exists, however. See Doane et al. (2008) for a discussion of the competitiveness of the secondary market prior to Order 736 . We are not aware of any similar studies of this market since Order 736 went into effect.
} 
As an illustration, consider the rate schedule of Florida Gas Transmission Company (FGT), one of the pipeline companies (or transporters) whose operations are relevant for our empirical analysis. ${ }^{40}$ For primary firm transportation contracts the shipper pays all three components. The currently effective maximum rate for the reservation fee is 46.94 $\$ /$ MMBtu. $^{41}$ The specified usage fee is $2.56 థ / M M B t u$ and the maximum fuel reimbursement charge is 3.17 percent of the value of the natural gas shipped.

A shipper who has a contract for interruptible primary services does not pay the reservation fee (because the transporter has the right to determine when the contracted volumes will be shipped), but does pay the usage fee and the fuel reimbursement charge. In what appears to be an unusual case, on FGT the usage fee for interruptible transportation services is larger than the total tariff for firm services. For FGT the maximum usage fee for interruptible services that corresponds to the firm contract usage fee above is 61.04 $\oplus /$ MMBtu.

Actual contracts can vary along a number of margins from the three part charges described above. For example, different classes of customers can be charged different prices, usage rates may vary with the distance the natural gas is shipped, and fuel reimbursement charges may be determined by the number of compressor stations through which contracted gas is shipped. In addition, the rates discussed above represent maximum rates, and negotiated rates with individual customers may be lower than these maximum rates.

\footnotetext{
${ }^{40}$ See http://fgttransfer.energytransfer.com/InfoPost/tariff/fgt/FGTTariff.pdf.

${ }^{41}$ FGT has different rate schedules for different classes of customers. The rates in the text are for FTS-1 customers.
} 


\section{B Graphical Representation of the Regional Market Model}

In this appendix, we provide and briefly discuss a graphical representation of a simple two-pipeline natural gas model. Even with only two pipelines, there are many options for how to represent the mathematical model presented in the text. For graphical tractability, as can be seen in figures B.1a, B.1b, and B.1c, we depict the two pipelines in the system as having different marginal costs, $M C_{1}=S_{1}$ and $M C_{2}=S_{2}$, and the same capacities, $q_{1}^{c}$ $=q_{2}^{c}$. The two marginal cost (supply) curves are drawn to be parallel, with different intercepts $S_{1}(0)$ and $S_{2}(0)$. The supply of natural gas from this system is the horizontal summation of the two marginal cost curves, subject to the constraint that the flow through each pipeline may not exceed its capacity. This yields the bold, kinked supply curve labeled $S_{1}+S_{2}=S_{M K T}$ in each of the three graphs below. For prices between $S_{1}(0)$ and $S_{2}(0)$, natural gas will be supplied only from pipeline 1 . For prices between $S_{2}(0)$ and $M C_{1}^{C}$, gas will be shipped through both pipelines. For prices greater than $M C_{1}^{C}$, the capacity constraint for the first pipeline is binding. If price is between $M C_{1}^{C}$ and $M C_{2}^{C}$ additional gas will be provided (only) by the second pipeline. If price exceeds $M C_{2}^{C}$, both pipeline constraints are binding and the supply curve for the system is vertical.

Figure B.1a illustrates Case A from the text. Both pipelines are at capacity, so total production is $Q^{C}$, the market price is $P_{A}^{*}$, and the shadow values of capacity are $\lambda_{1}=P_{A}^{*}$ $M C_{1}^{C}$ and $\lambda_{2}=P_{A}^{*}-M C_{2}^{C}$.

Figure B.1b corresponds to Case B from the text. The market clearing price is $P_{B}^{*}$ and the quantity is $Q_{T}^{*}$. The quantity $q_{1}^{C}$ is shipped through pipeline 1 , and $q_{2}^{*}$ is shipped through pipeline 2. The shadow value of capacity is $\lambda_{1}=P_{B}^{*}-M C_{1}^{C}$ for pipeline 1 and $\lambda_{2}=0$ for pipeline 2 .

Case $\mathrm{C}$ is depicted in figure B.1c. With the demand curve $D_{C}$, the market clearing price and quantity are $P_{C}^{*}$ and $Q_{T}^{*}$. The quantity $q_{1}^{*}$ is shipped through pipeline 1 , with $q_{2}^{*}$ being shipped through the second pipeline. Note that as the demand curve shifts further to the left, the market price will fall to a level less than $S_{2}(0)$ and the market clearing quantity will all be provided by pipeline 1 . 

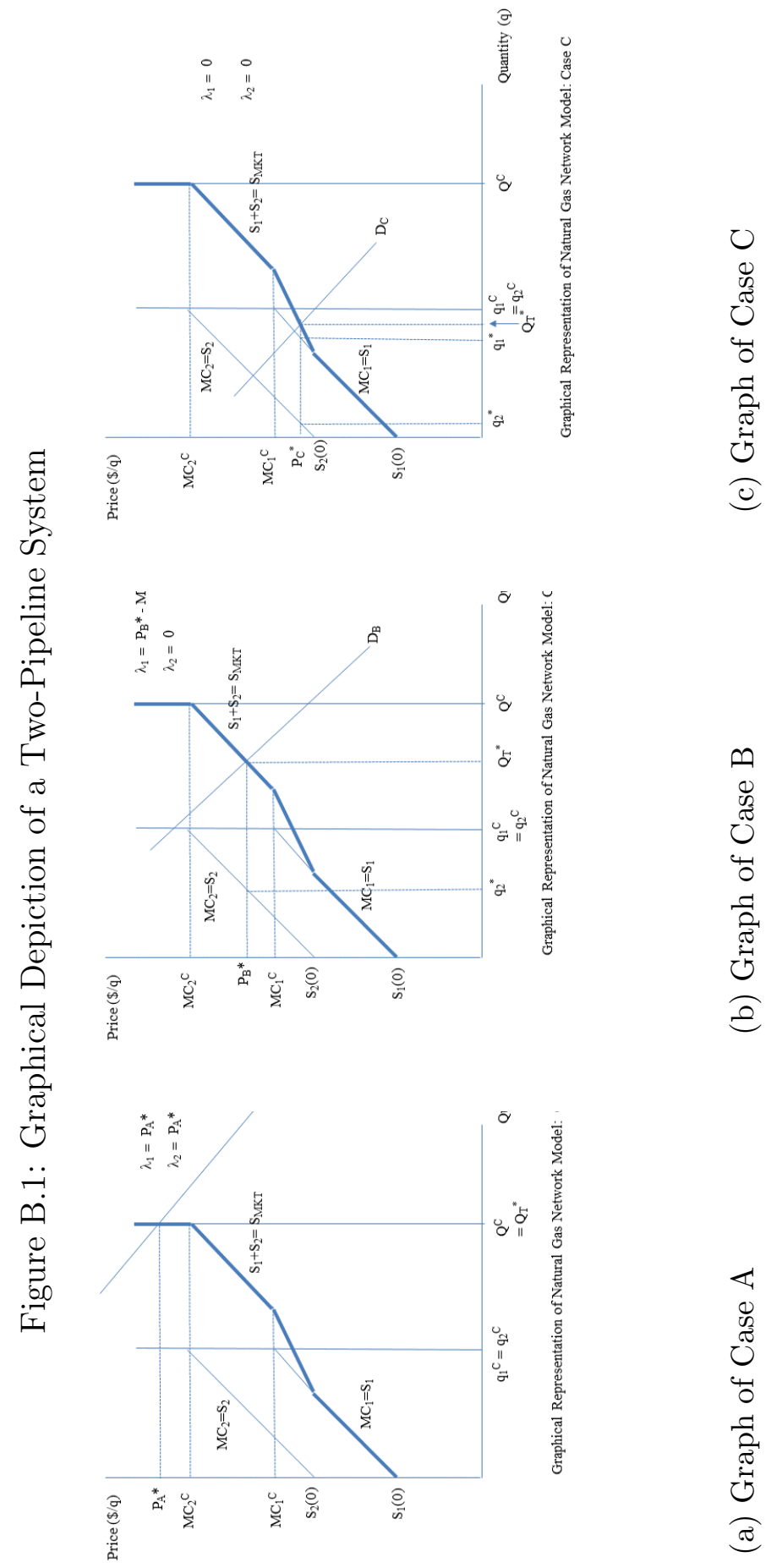


\section{Florida and Southern California Pipelines}

Natural gas consumption in Florida is dominated by the electric power sector, which accounts for over 80 percent of all consumption. The industrial sector consumes nearly 9 percent, while residential and commercial sectors combine for about 8 percent. Mt.

Vernon, a compressor station near the border of Mississippi and Alabama, is a point where capacity often binds on the FGT trunkline. A similar point on Gulfstream is Station 200 (St. 200 in figure 3) off the Florida Coast. The daily capacity and flow data for these two points can be seen in figures C.1 and C.2. It is notable that there are numerous instances in the two figures of daily flows reaching capacity.

As can be seen in figure 3, if a pipeline transporting natural gas into Southern California nears capacity during a period of high demand, there are three alternative pipelines through which adjustments might be made. Storage withdrawals and increased in-state production provide additional alternative supply sources. The availability of these alternative supply sources suggests the price responses to binding pipeline constraints will be lower in California than in the Florida markets we study. The responsiveness of storage withdrawals and in-state production to increased natural gas prices are not precisely known, but we expect them to be positive. In 2010, 32.4 percent of natural gas consumption in Southern California was in the electric power sector, 30.9 percent was in the industrial sector, 21.8 percent was in the residential sector, and 10.9 percent was in the commercial sector.

The Veyo compressor station, in the southwest corner of Utah, is a point where capacity sometimes binds along the Kern River pipeline. Potential bottlenecks on the El Paso system are in transporting gas west along the North system in Arizona, and in moving gas west from Texas into New Mexico. Along the Transwestern system, which transports gas west through Arizona, there is also a potential bottleneck at the West compressor station. The daily capacity and flow data for these points are displayed in figures C.3, C.4, C.5, and C.6. Because both Kern River and the El Paso North pipelines are above ground, their capacity fluctuates due to temperature changes. Falling flows in recent years through El Paso North have been attributed to falling production in the mature San Juan Basin fields that feed the pipeline. 
Figure C.1: FGT Mt. Vernon Throughput Capacity and Flows

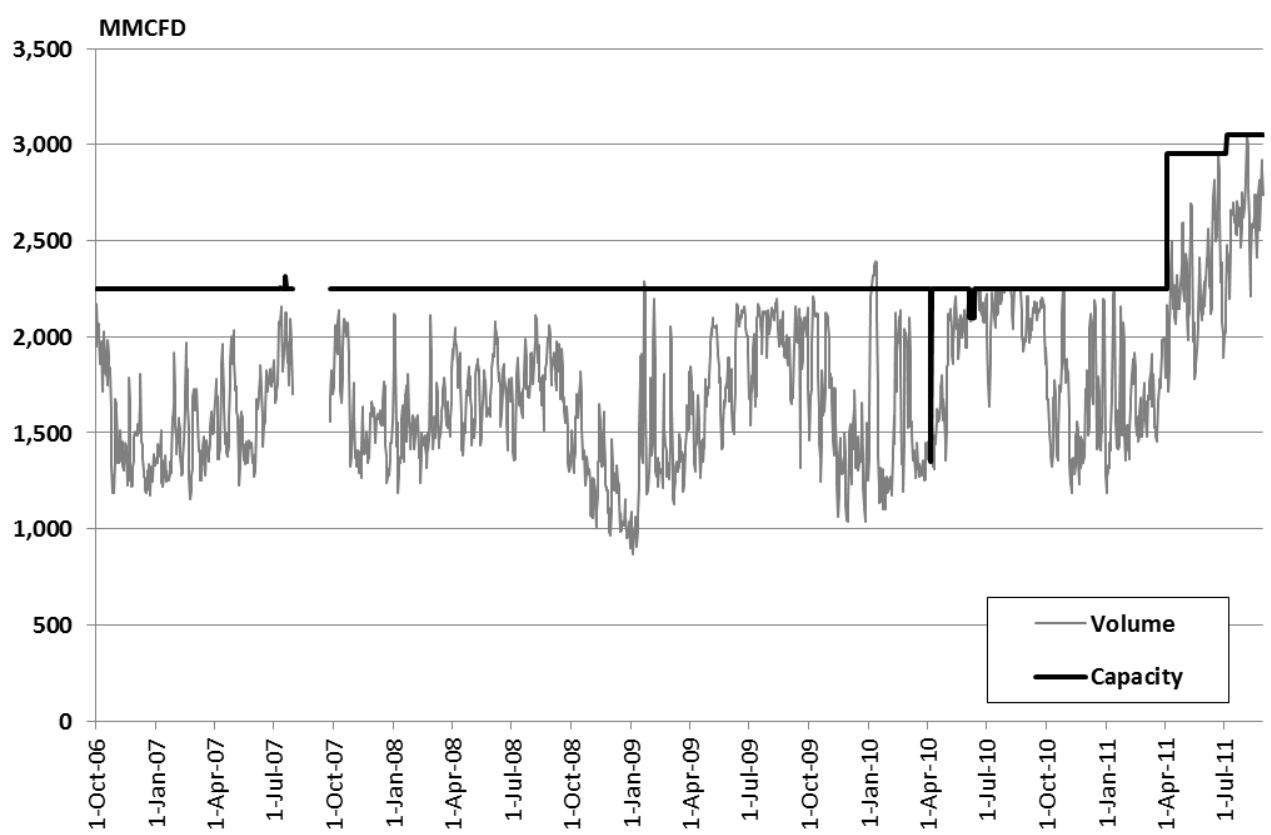

Figure C.2: Gulfstream Station 200 Throughput Capacity and Flows

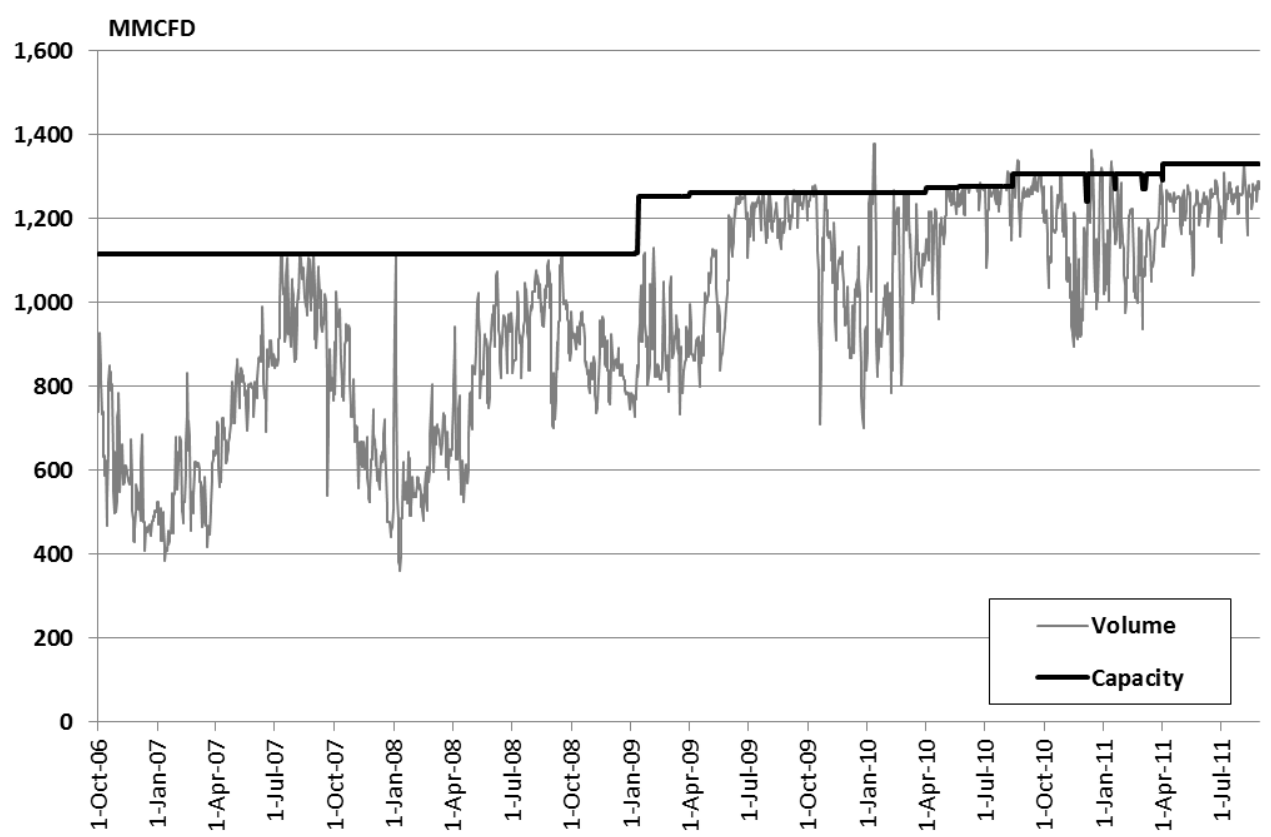


Figure C.3: Kern River Veyo Station Throughput Capacity and Flows

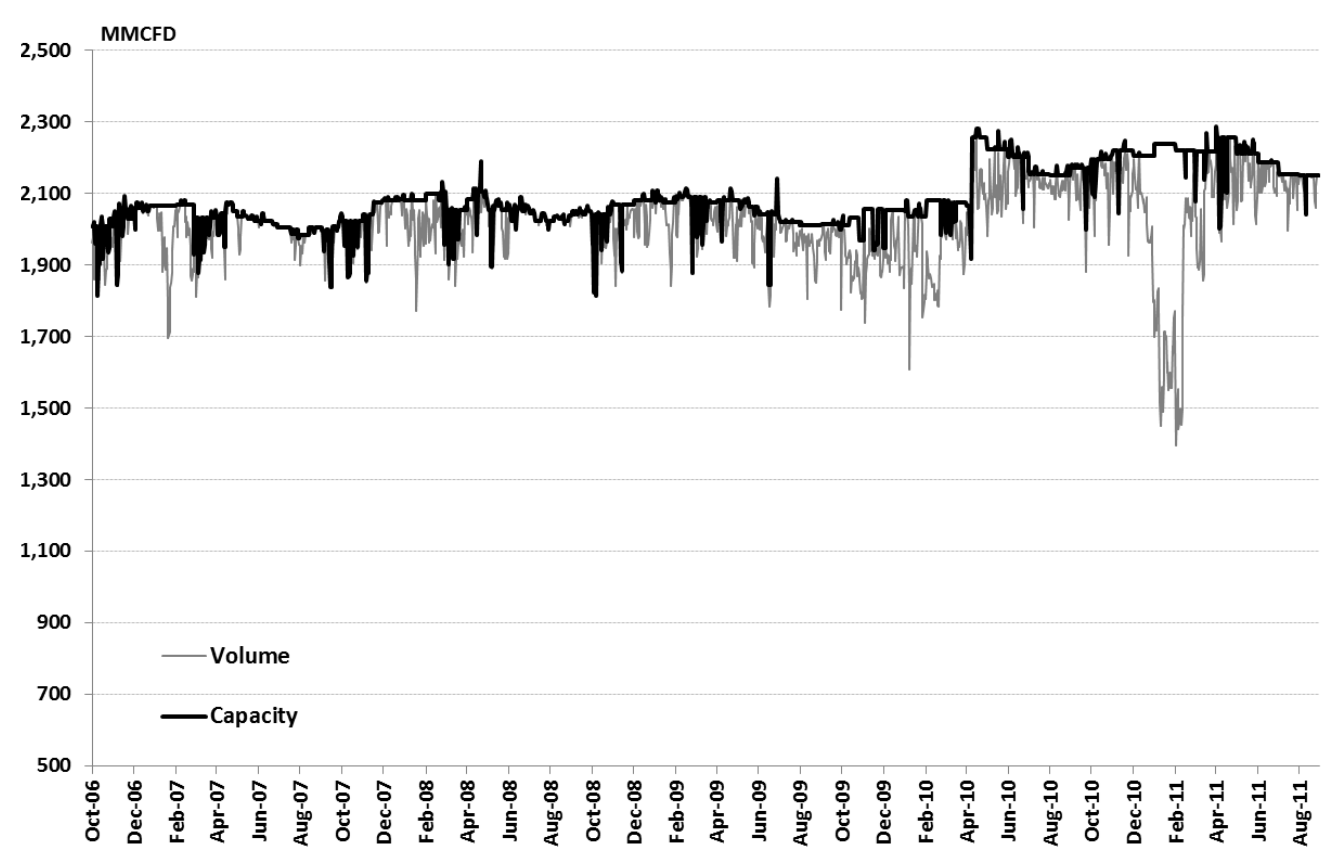

Figure C.4: Transwestern West Throughput Capacity and Flows

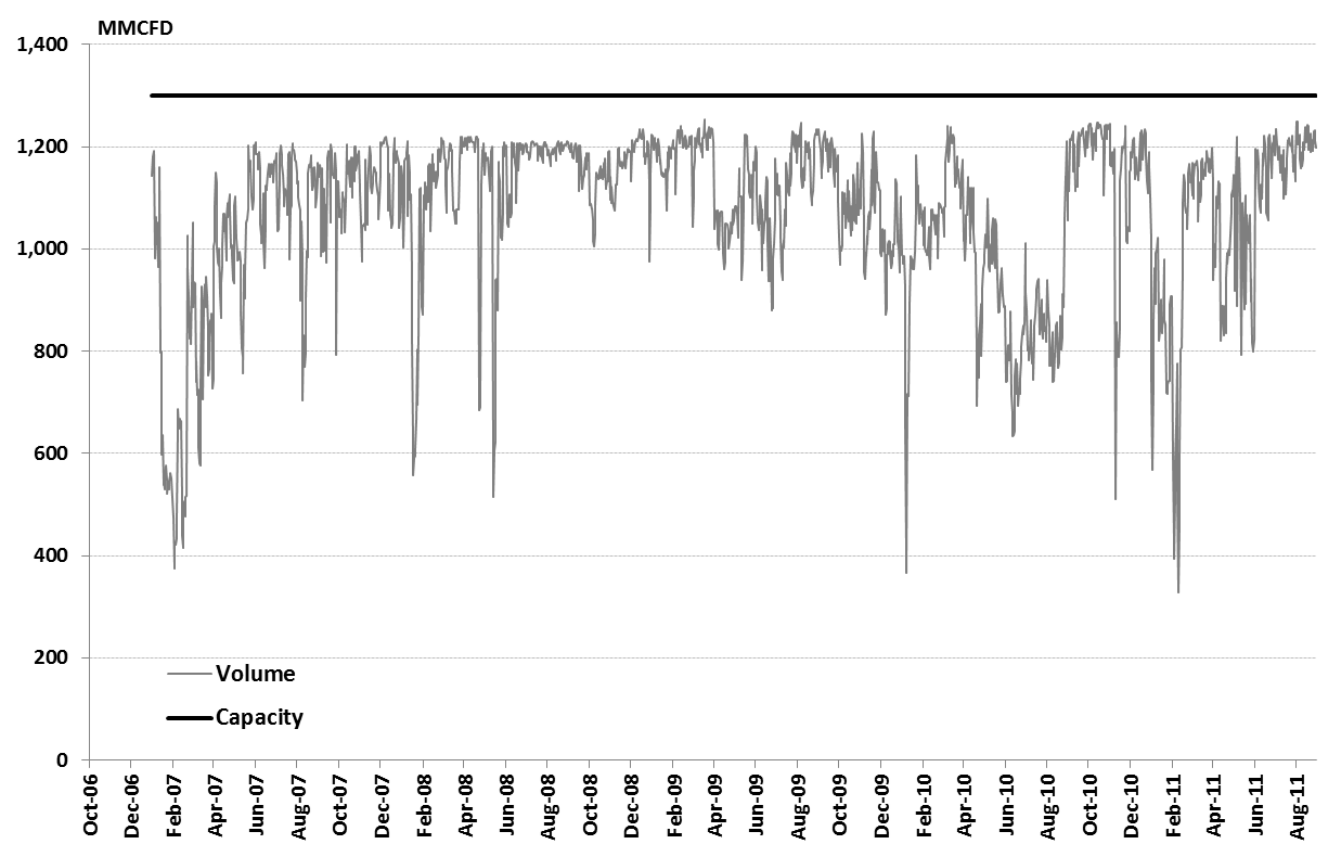


Figure C.5: El Paso North Throughput Capacity and Flows

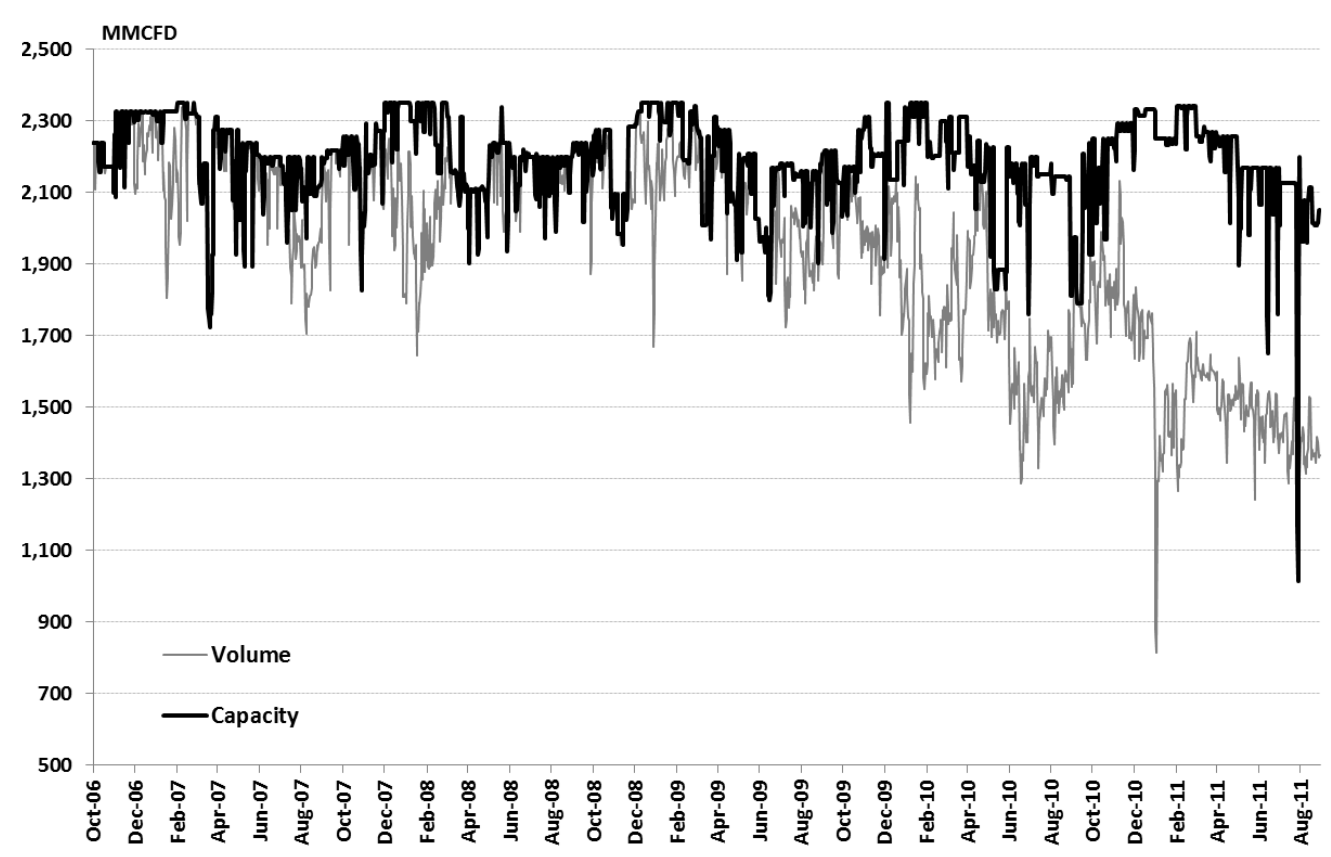

Figure C.6: El Paso South Throughput Capacity and Flows

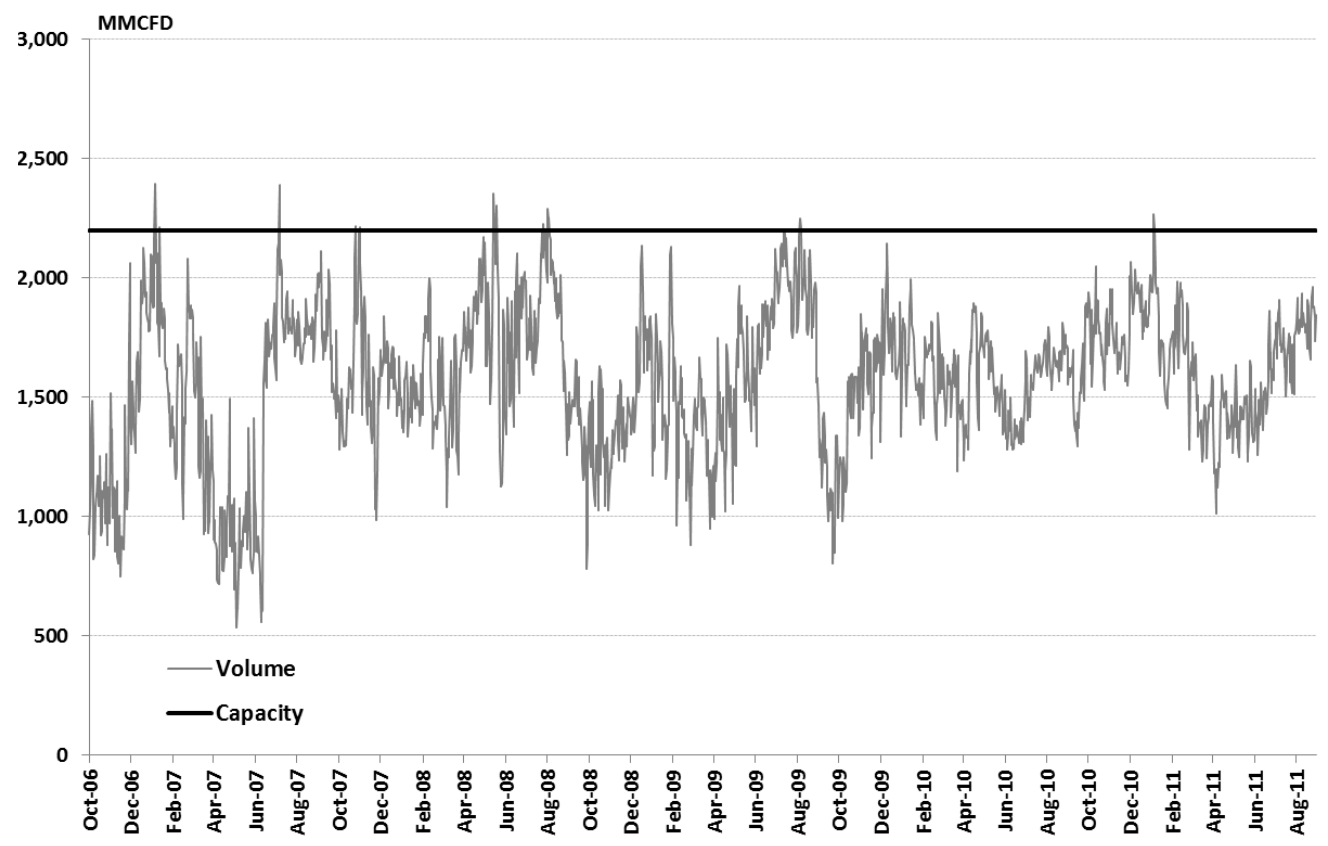




\section{Sources, Summary Statistics, and Cointegration Analysis for 14 Regional Markets}

In this appendix, we provide our data sources, as well as additional detail on our examination of the 14 regional prices for evidence regarding market integration. Table D.1 reports the sources for all the data we use in our empirical analysis and table D.2 presents summary statistics for the price data we obtained for 14 regions for the period from October 1, 2006 - August 29, 2011. Table D.3 presents the results of tests for the stationarity properties of each of the 14 regional price series in our data. The ADF tests we run indicate that each of the 14 price series is $\mathrm{I}(1)$ in levels and $\mathrm{I}(0)$ in differences.

Table D.4 presents the results from our tests for pairwise cointegration between each of the 14 price series. As indicated in section 4.1 in the text of the paper, we use the errors from each regression of one regional price on another regional price to conduct ADF tests for whether the coefficient on $\alpha_{1}$ in equation (5) is significantly less than 1.0. The null hypothesis in this test is that $\alpha_{1}$ is equal to 1.0 , or equivalently that the prices are not cointegrated. In table D.4 it is seen that the null hypothesis is rejected at standard significance levels for every pair of prices - that is, every pair of prices is cointegrated.

Table D.1: List of Data

\begin{tabular}{llll}
\hline Data & Units & Source & Frequency \\
\hline \hline Pipeline Capacities & MMcfd & LCI Inc. & Daily \\
Pipeline Flows & MMcfd & LCI Inc. & Daily \\
Natural Gas Prices & \$MMBtu & NGI Gas Daily & Daily \\
WTI Oil Spot Prices & \$MMBtu & EIA & Daily \\
Coal Prices & \$MMBtu & EIA & Monthly \\
Heating Degree Days & HDD & MSU-NOAA & Daily \\
Cooling Degree Days & CDD & MSU-NOAA & Daily \\
Industrial Output Prices & Index & BLS & Monthly \\
Producer Price Index & Index & BLS & Monthly \\
State Personal Income & Billion $\$$ & BEA & Monthly \\
Hurricane Shut-ins & MMcfD & BOEMRE & Incident Reports \\
\hline
\end{tabular}


Table D.2: Summary Statistics for 14 Regional Prices: October 1, 2006 - August 29, 2011

\begin{tabular}{lcccccc}
\hline Variable & Region & Mean & Std. Dev. & Min. & Max. & N \\
\hline \hline & & & & & & \\
Henry Hub Price & South & 5.79 & 2.23 & 1.84 & 13.31 & 1250 \\
Malin Price & Northwest & 5.48 & 2.03 & 2.23 & 12.31 & 1252 \\
PG\&E Citygate Price & West & 5.84 & 2.07 & 2.63 & 12.82 & 1252 \\
So Cal Avg Price & West & 5.42 & 2.02 & 2.22 & 12.68 & 1252 \\
Katy Hub Price & Texas & 5.60 & 2.13 & 1.95 & 12.98 & 1252 \\
FGT Z3 Citygate Price & Southeast & 6.73 & 2.65 & 2.26 & 18.00 & 1013 \\
Chicago Citygate Price & Midwest & 5.81 & 2.20 & 2.00 & 13.15 & 1252 \\
NE Columbia Price & Northeast & 6.01 & 2.32 & 1.94 & 13.85 & 1252 \\
Kingsgate Price & Northwest & 5.29 & 1.95 & 2.05 & 11.94 & 1221 \\
Kern River Hub Price & Rockies & 4.38 & 1.793 & 0.12 & 10.29 & 1252 \\
Opal Hub Price & Rockies & 4.39 & 1.794 & 0.12 & 10.26 & 1252 \\
Stanfield Price & Northwest & 5.40 & 2.00 & 2.14 & 12.08 & 1252 \\
FGT Z3 AL-MS Price & Southeast & 5.98 & 2.36 & 1.86 & 14.39 & 1252 \\
Waha Hub Price & Texas & 5.29 & 1.99 & 1.99 & 12.33 & 1252 \\
\hline Notes: All prices are in & realis & & & & &
\end{tabular}

Notes: All prices are in real 2011 dollars. 
Table D.3: Results of ADF Unit Root Tests on Regional Prices

\begin{tabular}{lcccc}
\hline & \multicolumn{2}{c}{ ADF on Levels } & \multicolumn{2}{c}{ ADF on First Difference } \\
Price Series & Test Statistic & p-Value & Test Statistic & p-Value \\
\hline \hline & -0.98 & 0.7623 & -30.05 & 0.0000 \\
Henry Hub & -1.39 & 0.5867 & -33.19 & 0.0000 \\
Malin & -1.26 & 0.6494 & -34.86 & 0.0000 \\
PG\&E Citygate & -0.88 & 0.7943 & -38.52 & 0.0000 \\
SoCal Avg. & -0.92 & 0.7822 & -27.08 & 0.0000 \\
Katy Hub & -2.13 & 0.2332 & -19.51 & 0.0000 \\
FGT Zone 3 Citygate & -1.42 & 0.5746 & -28.25 & 0.0000 \\
Chicago Citygate & -1.46 & 0.5531 & -28.90 & 0.0000 \\
NE Columbia & -2.02 & 0.2759 & -31.45 & 0.0000 \\
Kingsgate & -2.21 & 0.2024 & -38.17 & 0.0000 \\
Kern River & -2.24 & 0.1928 & -37.80 & 0.0000 \\
Opal Hub & -1.60 & 0.4822 & -32.87 & 0.0000 \\
Stanfield & -1.25 & 0.6530 & -29.22 & 0.0000 \\
FGT Zone 3 AL-MS & -0.93 & 0.7775 & -31.04 & 0.0000 \\
Waha Hub & 2011 & Ang & \\
\hline Notes: All pris
\end{tabular}

Notes: All prices are in real 2011 dollars. Augmented Dickey-Fuller (ADF) tests for unit roots are run on each of the 14 price series. The null hypothesis for the ADF test is that the series in question is non-stationary (i.e., it has a unit root). Test results in the two columns under the heading "ADF on Levels" indicate uniform failure to reject the null, or equivalently that all 14 price series are non-stationary in levels. Test results in the last two columns indicate uniform rejection of the null that each series is non-stationary in first differences, or equivalently that all 14 series are stationary in first differences. 


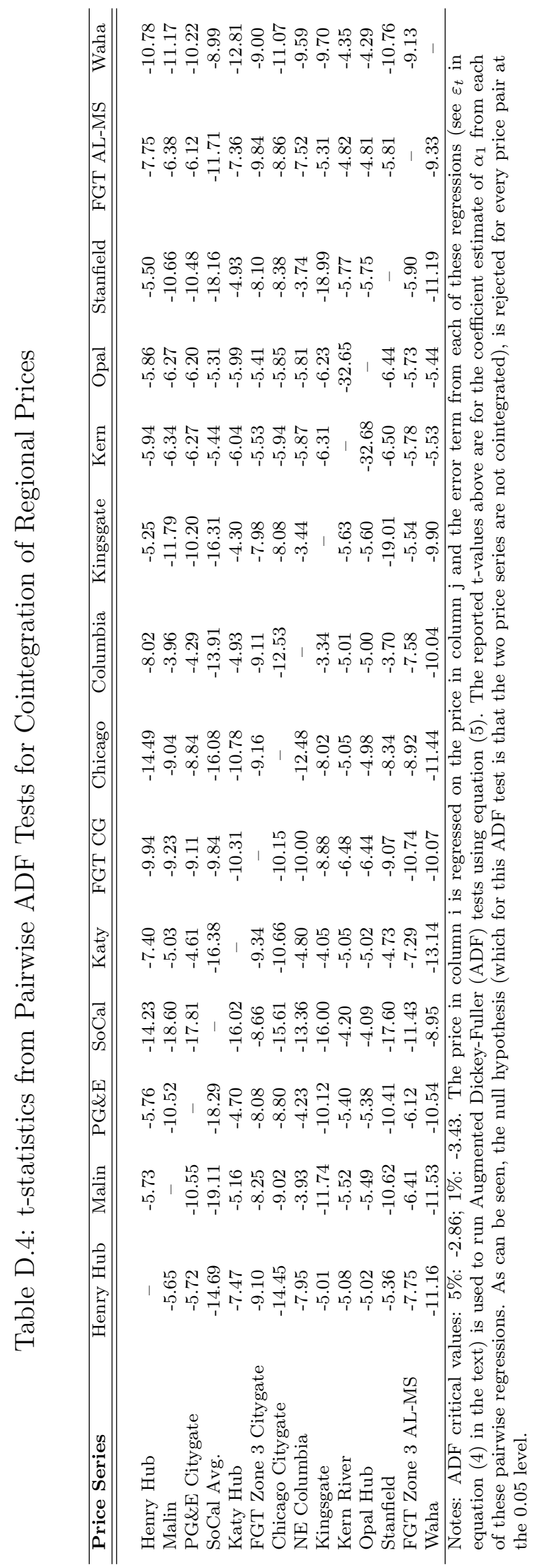




\section{E Supplementary Florida Regression Analyses}

In this appendix, we present and briefly discuss alternative specifications for the Florida regressions. We also provide detail on the price effects resulting from capacity constraints that are implied by the coefficients estimates in model 4 of table 6 in the text.

\section{Adding the Monthly Variables to Specifications in Table 6}

In table E.1, we present results from the same regression specifications as in table 6, models 1,3 , and 5, with the addition of the three variables that are available only at the monthly level - the price of coal, personal income, and the price index for industrial output. In table E.1, the difference between the three models is the definition of the capacity factor at which the pipeline capacity constraint becomes binding. As is evident, the three monthly variables are generally not individually significant, and their addition to the specifications in table 6 in the text does not have substantive impacts on the estimated coefficients of the other variables in the model. Most importantly, the addition of the three monthly variables has no qualitative impact on the values of the Binding Capacity variables.

\section{Individual Pipelines}

To this point, we have pooled all the flows and the stated capacities of the FGT and Gulfstream pipelines. In table E.2, we investigate the pipelines separately, as well as the price effects of interactions between flow levels in the two pipelines in the system. In model 1 , we define three binary capacity measures. The first two variables are assigned a value of one when one of the two pipelines is full to stated capacity and the other is not, with both variables assigned a value of zero if neither pipeline is full or if both pipelines are full. The third variable is assigned a value of one when both pipelines are full to their stated capacities. These three variables have a value of one on 22,24 , and seven days, respectively. The estimated coefficients on these variables indicate the difference between prices on days when these conditions hold relative to day when neither of the two pipelines is full. The separate treatment of the capacity variables in the two pipelines has little impact on the estimated coefficients on the other variables in the model, so we report only the coefficients for the three variables described above. As can be seen, the estimated coefficients on each of the three variables is significantly greater than zero. The estimated price impact when FGT is full and Gulfstream is not, is roughly half as large as when the reverse holds $(\$ 1.10$ as compared to $\$ 2.04$ ), although these two values are not statistically different. When both 
pipelines are full on the same day, prices are $\$ 4.66$ greater than on days when neither of the two pipelines is full. This price impact is statistically greater than each of the other two individual price impacts and is not statistically different from the estimated coefficients on the Binding Capacity 100+\% variable in the final column of table 6 and in table 7 .

In model 2 of table E.2, we explore whether the price effects of capacity constraints in one pipeline are affected by flow levels in the other. The variable names are intuitive-for example, the zero-one variable FGT 95-99, GS 90-95 is assigned a value of one on days when the flow in the FGT pipeline is between 95 and 99 percent of stated capacity and the flow in the Gulfstream pipeline is between 90 and 95 percent of its capacity. The estimated coefficient on that variable measures the average difference between prices on days when flows are in these ranges and days on which flows in one or both of the pipelines are less than 90 percent of their stated capacities. The results suggest that the price effects of capacity or near-capacity flows in each individual pipeline depends on the flow level in the other pipeline.

Figures E.1a and E.1b display the coefficient estimates from model 2 as two-dimensional depictions of the relationships between price and capacity factors in the two pipelines. In figure E.1a, each of the four lines shows the impacts on price of an increase in the FGT capacity factor for one of four different levels of the Gulfstream capacity factor. The top line in the figure shows the impact on prices of each of four different levels of daily FGT flows on days when the Gulfstream pipeline is at full capacity. When the Gulfstream pipeline is full and the FGT pipeline capacity factor is between 99 and 100 percent, the price is $\$ 5.62$ greater than on days when one or the other or both of the pipelines are less than 90 percent full. If the price impacts of increasing flow in the FGT pipeline were independent of the flow levels in the Gulfstream pipeline, then all four of the lines in this figure would be coincident. The fact that they are not suggests the presence of interactions. Moreover, most of the impacts of increases in the FGT capacity factor are about $\$ 1$ (and are mostly statistically insignificant) except when the Gulfstream pipeline is full. In those instances, the price impacts of all four FGT levels shown are statistically greater than zero, and when the FGT pipeline is flowing at 99 percent or more of its stated capacity, prices are more than $\$ 5$ greater than when flows are at less than 90 percent of capacity in one or the other, or both, of the pipelines.

In figure E.1b, each of the four lines shows the price impacts of an increase in the Gulfstream capacity factor for one of four different levels of the FGT capacity factor. As in the previous figure, the fact that the four lines are not coincident indicates important 
interactions. For any given level of the Gulfstream capacity factor, the two lines for when the FGT capacity factor is from 99-100 percent and 100 percent or greater lie above the lines for the two lower level of FGT capacity factors (although several of the price effects are not statistically different from each other). For all four of the FGT capacity factor levels, the jump in price comes predominately when the Gulfstream pipeline is at full capacity, and not before. Moreover, the increase in price when Gulfstream becomes full is much greater when the FGT flow is at 99 percent or more of its capacity.

This analysis of the individual pipeline effects offers two insights. First, although our results in model 1 of table E.2 suggest that there are substantial price effects when either of the pipelines is flowing at full capacity, they also suggest that the price impacts are substantially greater when both the pipelines are at full capacity. This is consistent with our earlier results, which indicate that price effects are largely a result of no pathways being available to get more gas to the regional market. Second, our results in model 2 suggest there are substantial price effects due to interactions between flows in the two pipelines, but only when both pipelines are flowing at levels very close to capacity. This is also consistent with our earlier results reported in table 7 . These insights taken together suggest that treating the two Florida pipelines individually reveals interesting and important price effects related to pipeline capacity constraints. This approach also, however, causes one to overlook important interactions between flow levels in the system of pipelines that result in substantially larger price effects related to capacity constraints.

\section{Calculating Capacity Impacts with Multiplicative Interactive Terms}

In models 2 and 4 of table 6 in the text, changes in the short-run demand shifters, HDD and CDD, have greater impacts when the pipelines are full, or nearly so, than on other days. It is informative to compare the impacts of capacity being binding from the specification in models 2 and 4 of table 6 with those in models 1 and 3 in table 6 . Here, we work through these calculations for model 4, where the threshold for the Binding Capacity variable is 99 percent. The estimate of this impact in model 3 is $\$ 1.71$.

To estimate comparable values for model 4 in table 6 , we have to calculate marginal effects taking all interaction terms into account. We make this calculation first on an average HDD day and then on an average CDD day, where the average HDD value is taken over the eight days (out of the 44 days with flow greater than 99 percent of capacity) with positive HDD values, and the average CDD value is taken over the 36 days with positive CDD values. Using this approach, our estimates of the impacts of binding capacity 
constraints on HDD and CDD days are $\$ 4.31$ and $\$ 1.13$, respectively. Both these estimates are significantly different from zero at the 0.01 level. The HDD marginal effect is also significantly greater than the CDD marginal impact. Given that Florida is a market with hot and humid summers and mild winters, we might expect more adaptations have been made to accommodate hot rather than cold days. These two estimates can be compared with the $\$ 1.71$ estimate of binding capacity mentioned above by calculating the weighted average of the estimates, where the weights are the proportions of HDD and CDD days out of the 44 days defined to have binding capacity for this exercise. This weighted average is $\$ 1.71$ in model 4 , the same as in model 3 (the estimates are not identical when calculated to further precision levels). 
Table E.1: Florida Regression Results with Monthly Variables - All Pipelines

\begin{tabular}{lccc}
\hline & $(1)$ & $(2)$ & $(3)$ \\
\hline \hline & & & \\
Constant & -16.4429 & -11.7859 & $-21.5055^{*}$ \\
& $(14.5473)$ & $(13.5640)$ & $(11.0299)$ \\
Real HH Price & $1.0885^{* * *}$ & $1.0342^{* * *}$ & $1.0335^{* * *}$ \\
Real WTI Price & $(0.0710)$ & $(0.0574)$ & $(0.0560)$ \\
& $0.0775^{* *}$ & $0.0798^{* *}$ & $0.0670^{* *}$ \\
Real Coal Price & $(0.0348)$ & $(0.0317)$ & $(0.0307)$ \\
& 0.5452 & 0.1895 & 0.6803 \\
Monthly FL Personal Income & $(0.7587)$ & $(0.6848)$ & $(0.5315)$ \\
& 22.9468 & 16.6940 & $29.1404^{* *}$ \\
Real Ind. Price Index-FL & $(16.2284)$ & $(15.4124)$ & $(12.2571)$ \\
& -0.0589 & -0.0408 & $-0.0559^{*}$ \\
Heating Degree Days & $(0.0419)$ & $(0.0338)$ & $(0.0339)$ \\
& $0.1798^{* * *}$ & $0.1893^{* * *}$ & $0.1747^{* * *}$ \\
Cooling Degree Days & $(0.0364)$ & $(0.0395)$ & $(0.0367)$ \\
Hurricane Shutins, Bcfd & $0.1120^{* * *}$ & $0.1206^{* * *}$ & $0.1263^{* * *}$ \\
& $(0.0167)$ & $(0.0192)$ & $(0.0178)$ \\
Binding Capacity 95+\% & $0.5232^{* * *}$ & $0.4330^{* * *}$ & $0.4841^{* * *}$ \\
& $(0.1036)$ & $(0.0955)$ & $(0.0900)$ \\
Binding Capacity 99+\% & $0.7347^{* * *}$ & & \\
& $(0.2187)$ & & \\
Binding Capacity 100+\% & & $1.6138^{* * *}$ & \\
& & $(0.4877)$ & \\
N & & & $4.6149^{* * *}$ \\
\hline Notes: The & & & $(1.0264)$ \\
& 961 & 961 & 961 \\
\hline
\end{tabular}

Notes: The dependent variable in all regressions is the daily natural gas price for Florida for the period Oct. 6, 2006 - Aug. 29, 2011. Binding Capacity 95+\% is a binary variable assigned a value of one if daily flow is 95 percent or more of stated system capacity, and a value of zero otherwise. Binding Capacity $99+\%$ and $100+\%$ are defined similarly. Newey-West standard errors are in parentheses. All specifications include month-of-year fixed effects (with December as the excluded month), as well as year fixed effects (with 2006 as the excluded year). All prices are expressed in real 2011 dollars. ${ }^{* * *} \mathrm{p}<0.01,{ }^{* *} \mathrm{p}<0.05,{ }^{*} \mathrm{p}<0.1$. All $\mathrm{p}$-values are for two-tailed tests. 
Table E.2: Price Effects of Individual Pipelines and Interactions in Florida

\begin{tabular}{|c|c|c|}
\hline & (1) & $(2)$ \\
\hline Both Capacity 100+\% & $\begin{array}{c}4.6593^{* * *} \\
(1.0178)\end{array}$ & $\begin{array}{c}4.9197^{* * *} \\
(0.9978)\end{array}$ \\
\hline FGT $100+\%$, GS $<100 \%$ & $\begin{array}{c}1.0952^{* * *} \\
(0.4036)\end{array}$ & \\
\hline GS $100+\%$, FGT $<100 \%$ & $\begin{array}{c}2.0386^{* *} \\
(0.8579)\end{array}$ & \\
\hline FGT 90-95, GS 100+ & & $\begin{array}{c}1.4627^{* * *} \\
(0.4675)\end{array}$ \\
\hline FGT 95-99, GS 90-95 & & $\begin{array}{c}1.2547 \\
(0.8270)\end{array}$ \\
\hline FGT 95-99, GS 95-99 & & $\begin{array}{l}0.3038^{*} \\
(0.1727)\end{array}$ \\
\hline FGT 95-99, GS 99-100 & & $\begin{array}{c}0.2250 \\
(0.1676)\end{array}$ \\
\hline FGT 95-99, GS 100+ & & $\begin{array}{c}2.1806 \\
(1.3766)\end{array}$ \\
\hline FGT 99-100, GS 95-99 & & $\begin{array}{l}1.1498 \\
(0.9444)\end{array}$ \\
\hline FGT 99-100, GS 99-100 & & $\begin{array}{c}1.0953^{* * *} \\
(0.2717)\end{array}$ \\
\hline FGT 99-100, GS 100+ & & $\begin{array}{l}5.7783^{*} \\
(3.0951)\end{array}$ \\
\hline FGT 100+, GS 95-99 & & $\begin{array}{c}0.5612^{* *} \\
(0.2609)\end{array}$ \\
\hline FGT 100+, GS 99-100 & & $\begin{array}{c}1.5772^{* * *} \\
(0.4515)\end{array}$ \\
\hline FGT 90-95, GS 90-95 & & $\begin{array}{c}0.9354^{* *} \\
(0.4009)\end{array}$ \\
\hline FGT 90-95, GS 95-99 & & $\begin{array}{c}0.1167 \\
(0.0922)\end{array}$ \\
\hline FGT 90-95, GS 99-100 & & $\begin{array}{c}0.1537 \\
(0.2076)\end{array}$ \\
\hline $\mathrm{N}$ & 961 & 961 \\
\hline \multicolumn{3}{|c|}{$\begin{array}{l}\text { Notes: The dependent variable in all regressions is the daily natural gas price for } \\
\text { Florida for the period Oct. } 6,2006 \text { - Aug. } 29,2011 . \text { Both Capacity } 100+\% \text { is } \\
\text { a binary variable assigned a value of one if daily flow is } 100 \text { percent or more of } \\
\text { stated capacity for both pipelines, and a value of zero otherwise. Other binary } \\
\text { flow variables are defined similarly. Newey-West standard errors are in parenthe- } \\
\text { ses. All specifications include month-of-year fixed effects (with December as the } \\
\text { excluded month), year fixed effects (with } 2006 \text { as the excluded year), as well as } \\
\text { the additional controls in table } 6 \text {. All prices are expressed in real } 2011 \text { dollars. } \\
* * * p<0.01,{ }^{* *} \mathrm{p}<0.05, * \mathrm{p}<0.1 \text {. All p-values are for two-tailed tests. }\end{array}$} \\
\hline
\end{tabular}


Figure E.1: Florida Interactive Pipeline Effects

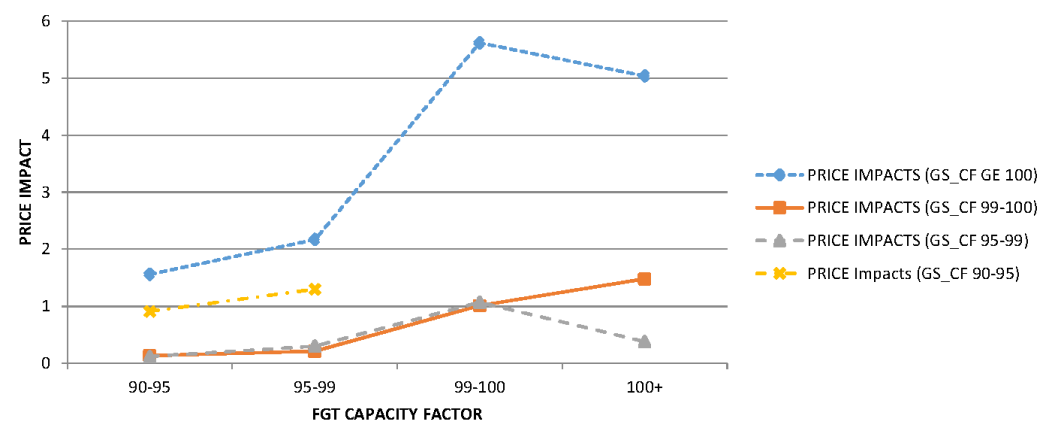

(a) Price Impacts of Changes in FGT Capacity Levels for Given Levels of Gulfstream Capacity Factor

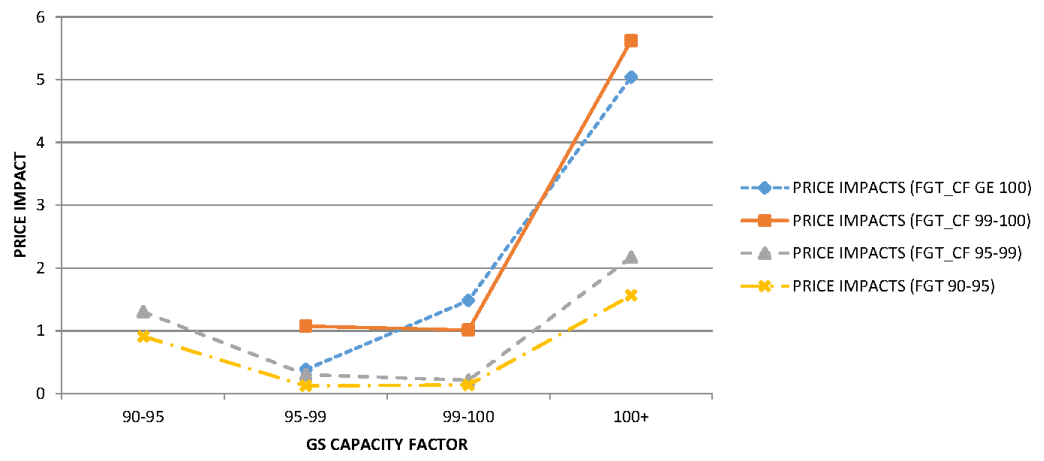

(b) Price Impacts of Changes in Gulfstream Capacity Levels for Given Levels of FGT Capacity Factor 